\title{
TLR4/MyD88-induced CD11b+Gr-1intF4/80+ non-migratory myeloid cells suppress Th2 effector function in the lung
}

\author{
M Arora ${ }^{1}$, SL Poe ${ }^{1,2,4}$, TB Oriss ${ }^{1,4}$, N Krishnamoorthy ${ }^{1,4}$, M Yarlagadda $^{1}$, SE Wenzel ${ }^{1}$, TR Billiar $^{3}$, \\ A Ray ${ }^{1,2}$ and P Ray ${ }^{1,2}$
}

In humans, environmental exposure to a high dose of lipopolysaccharide (LPS) protects from allergic asthma, the immunological underpinnings of which are not well understood. In mice, exposure to a high LPS dose blunted house dust mite-induced airway eosinophilia and T-helper 2 (Th2) cytokine production. Although adoptively transferred Th2 cells induced allergic airway inflammation in control mice, they were unable to do so in LPS-exposed mice. LPS promoted the development of a $\mathrm{CD} 11 \mathrm{~b}+\mathrm{Gr} 1^{\text {int }} \mathrm{F} 4 / 80^{+}$lung-resident cell resembling myeloid-derived suppressor cells in a Toll-like receptor 4 and myeloid differentiation factor 88 (MyD88)-dependent manner that suppressed lung dendritic cell (DC)-mediated reactivation of primed Th2 cells. LPS effects switched from suppressive to stimulatory in MyD88-/- mice. Suppression of Th2 effector function was reversed by anti-interleukin-10 (IL-10) or inhibition of arginase 1. Lineage ${ }^{\text {neg }}$ bone marrow progenitor cells could be induced by LPS to develop into CD11 ${ }^{+} \mathrm{Gr} 1^{\text {int }} \mathrm{F} 4 / 80^{+}$cells both in vivo and in vitro that when adoptively transferred suppressed allergen-induced airway inflammation in recipient mice. These data suggest that $\mathrm{CD} 11 \mathrm{~b}^{+} \mathrm{Gr}{ }^{1 \mathrm{int}} \mathrm{F} 4 / 80^{+}$cells contribute to the protective effects of LPS in allergic asthma by tempering Th2 effector function in the tissue.

\section{INTRODUCTION}

The incidence of atopy and asthma has greatly increased over recent years, concomitant with an improved hygienic status in the industrialized world. This suggests some form of environmental control on the development of allergic diseases. The hygiene hypothesis was invoked in 1989 to explain the inverse relationship between the risk of an allergic disease, hay fever, and family size. ${ }^{1}$ This hypothesis contends that in recent years, reduced microbial exposure in early life because of improved sanitary conditions and altered lifestyles has caused an increase in allergic diseases including asthma in developed countries. Several studies have supported the concept of the hygiene hypothesis. For example, an inverse association was noted between delayed-type hypersensitivity responses to tuberculin, a measure of responses to Mycobacterium tuberculosis, and serum immunoglobulin E titer, an indicator of the allergic burden. ${ }^{2} \mathrm{~A}$ lower incidence of allergic disease was reported in children enrolled early in day care. ${ }^{3}$ High levels of endotoxin, measured in dust samples collected from mattresses, was shown to be inversely related to the occurrence of hay fever, atopic asthma, and atopic sensitization among children raised in farms in rural areas in Europe. ${ }^{4}$ Initially, this observed inverse relationship between lipopolysaccharide (LPS) and allergic disease was attributed to ( $\mathrm{T}$ helper (Th)1/Th2) cross-regulation. ${ }^{2,5}$ However, it has become apparent after many studies that the underlying mechanism of the hygiene hypothesis is not Th1/Th2 cross-regulation. For example, in the studies of Braun-Fahrlander et al., ${ }^{4}$ LPS exposure was found to correlate with the inability of the children's blood leukocytes to produce both Th1 and Th2 cytokines, showing an overall downregulation of immune responses. It should be noted that not only have atopic diseases been on the rise in recent years, but so have autoimmune diseases such as diabetes mellitus and multiple sclerosis, ${ }^{6}$ such that investigators have begun to search for a common denominator for this increase in immune-mediated disorders. The contribution of

${ }^{1}$ Division of Pulmonary, Allergy and Critical Care Medicine, Department of Medicine, Pittsburgh, Pennsylvania, USA. ${ }^{2}$ Department of Immunology, University of Pittsburgh School of Medicine, Pittsburgh, Pennsylvania, USA. ${ }^{3}$ Department of Surgery, University of Pittsburgh School of Medicine, Pittsburgh, Pennsylvania, USA. ${ }^{4}$ These authors contributed equally to this work.. Correspondence: P Ray (rayp@pitt.edu) or A Ray (raya@pitt.edu)

Received 19 February 2010; accepted 21 June 2010; published online 21 July 2010. doi:10.1038/mi.2010.41 
immunosuppressive mechanisms underlying the hygiene hypothesis is being increasingly entertained. ${ }^{4}$

To better understand the mechanism by which LPS inhibits allergic responses, we examined the effect of LPS on the status of myeloid cells in the lung in adult mice. Continual exposure to LPS induced the generation of a suppressive myeloid cell type that expressed CD11b, Gr1 at intermediate levels, and F4/80, the combination of which distinguished it from neutrophils, macrophages, and dendritic cells (DCs). The cells resembled previously described hematopoietic stem and progenitor cell-derived myeloid cells in specific tissues including the lung whose numbers were shown to expand in the presence of Toll-like receptor (TLR) agonists such as LPS. ${ }^{7}$ The LPS-induced myeloid cells did not traffic to lung-draining lymph nodes (LNs) and did not affect T-cell functions in the LNs. However, the cells suppressed Th2 effector function in the lung tissue, which was in alignment with their tissue-dwelling characteristic. DC-induced signal transducer and activator of transcription 5 (STAT5) activation, GATA binding protein 3 (GATA-3) upregulation, and cytokine production in primed Th2 cells were inhibited by the LPS-induced myeloid cells. The cells could be generated by a combination of LPS and granulocyte-macrophage colonystimulating factor (GM-CSF) from lineage ${ }^{\text {neg }}$ progenitor cells. Adoptive transfer of the in vitro- or in vivo-derived cells efficiently inhibited allergen-induced airway inflammation. Our findings show that exposure of the lungs of adult mice to a high dose of LPS induces a myeloid suppressive cell type that serves to temper the function of effector Th2 cells.

\section{RESULTS}

\section{Exposure of the lung to bacterial LPS promotes a $\mathrm{CD} 11 b^{+} \mathrm{Gr}{ }^{\text {int }} \mathrm{F} 4 / 80^{+}$cell type that is distinct from neutrophils}

LPS has been associated with both promotion and inhibition of allergic airway inflammation. A dose $<1 \mathrm{ng}$ of LPS induces tolerance, $\sim 100$ ng promotes allergic airway inflammation, whereas a higher dose ( $\mu \mathrm{g}$ range) inhibits the same process. ${ }^{8,9}$ LPS in the range of 30,000 endotoxin units $(3 \mu \mathrm{g})$ per $\mathrm{m}^{2}$ of mattress surface area was detected in farms in which children were found to be protected from allergic diseases including hay fever and asthma. ${ }^{4}$ We examined the effect of different doses of LPS on the frequency of $\mathrm{CD} 11 \mathrm{~b}^{+} \mathrm{Gr} 1^{+}$cells, as this dual expression would be expected to reveal neutrophils, which should be recruited by LPS to the lungs. Interestingly, LPS not only caused the expected increase in the frequency of a CD11 b ${ }^{+} \mathrm{Gr} 1^{\text {hi }}$ population, but also a second population, with the phenotype $\mathrm{CD} 11 \mathrm{~b}^{+} \mathrm{Gr} 1^{\text {int }}$ also promoted by LPS (Figure 1a). The frequency of the $\mathrm{CD} 11 \mathrm{~b}^{+} \mathrm{Gr} 1^{\text {int }}$ population increased with each instillation of LPS and was discernible as early as $24 \mathrm{~h}$ after the first instillation. To characterize each population further, the cells were sorted as shown (Figure 1b). As expected, the $\mathrm{Gr}{ }^{\text {hi }}$ population showed myleoperoxidase activity characteristic of neutrophils but the $\mathrm{Gr} 1^{\text {int }}$ cells did not express myleoperoxidase (Figure 1c).

The cells were also examined for the expression of F4/80, which is not expressed by neutrophils. ${ }^{10,11}$ Although the neutrophils were $\mathrm{F} 4 / 80^{-}$, the $\mathrm{Gr} 1^{\text {int }}$ cells were $\mathrm{F} 4 / 80^{+}$. Collectively, the features of the Gr $1^{\text {int }}$ cells resembled those of myeloidderived suppressor cells (MDSCs) isolated from tumor sites that have the phenotype $\mathrm{CD} 11 \mathrm{~b}{ }^{+} \mathrm{Gr} 1^{+} \mathrm{F} 4 / 80^{+} .{ }^{12}$ We also examined the expression of other molecules such as CD115 (M-CSF receptor), CD124 (interleukin-4 (IL-4) receptor $\alpha$ chain), CD62L, CD34, and CD206, which have been associated with tumor-infiltrating MDSCs. ${ }^{13}$ However, the expression of these molecules is not essential for the suppressive function of MDSCs. ${ }^{12}$ The $\mathrm{CD} 11 \mathrm{~b}^{+} \mathrm{Gr} 1^{\text {int }} \mathrm{F} 4 / 80^{+}$cells induced by LPS in the lung did not express CD115, CD124, CD62L, CD34, or CD206 (Figure 1d). The LPS-induced cells also expressed intermediate/low levels of CD11c. As shown in Figure 1e, the $\mathrm{Gr} 1^{\text {hi }}$ and $\mathrm{Gr} 1^{\text {int }}$ populations were morphologically distinct. As expected, the $\mathrm{CD} 11 \mathrm{~b}^{+} \mathrm{Gr} 1^{\mathrm{hi}} \mathrm{F} 4 / 80^{-}$cells showed neutrophil-like morphology with characteristic lobular-shaped nuclei. Morphological assessment of $\mathrm{CD} 11 \mathrm{~b}^{+} \mathrm{Gr} 1^{\text {int }} \mathrm{F} 4 / 80^{+}$ cells revealed the presence of myeloid cells similar to the $\mathrm{Gr}^{+} \mathrm{CD} 11 \mathrm{~b}^{+}$cells described in murine models of cancer and trauma with many cells showing the presence of ring-shaped nuclei. ${ }^{12-14}$

As specific antibodies recognizing the two epitopes of Gr1, Ly6C and Ly6G, are available (anti-Gr1 recognizes both), we also characterized the LPS-induced Gr $1^{\text {int }}$ cells on the basis of expression of the two epitopes. The non-neutrophilic LPSinduced cells consisted of two subsets based on their differential Ly6C expression. Among the CD11b + cells gated on

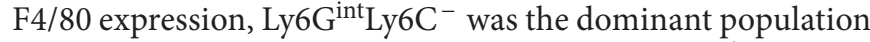
expanded by LPS treatment, with the Ly6 $\mathrm{G}^{\text {int }} \mathrm{Ly} 6 \mathrm{C}^{\mathrm{lo}}$ population being the minor subset (right panel in Supplementary Figure S1 online). As inflammatory monocytes express Ly6C but do not express Ly6G, ${ }^{15}$ the Gr $1^{\text {int }}$ cells did not seem to be inflammatory monocytes.

\section{The $\mathrm{CD} 11 \mathrm{~b}+\mathrm{Gr} 1^{\text {int }} \mathrm{F} 4 / 80^{+}$cell type is phenotypically distinguishable from lung $\mathrm{DCs}$}

We next compared the Gri ${ }^{\text {int }}$ cells with conventional DCs (cDCs) isolated side-by-side from the lungs of the same LPStreated mice, the DCs being identified based on CD11c expression and low autofluorescence (Figure 2a). The cells were cultured briefly to identify the cytokines they produce. The $\mathrm{CD} 11 \mathrm{~b}^{+} \mathrm{Gr} 1^{\text {int }} \mathrm{F} 4 / 80^{+}$cells produced higher levels of IL- 6 and GM-CSF when compared with equal numbers of cultured cDCs (Figure 2b). The cDCs, however, secreted more IL-12p40 (Figure 2b). The cDCs expressed higher levels of cell surface markers such as major histocompatibility complex class II, CD86, and $\mathrm{CD} 40$, and the reverse was true for CD80 (Figure 2c). High level of CD80 expression is a characteristic of MDSCs and is important for their suppressive function. ${ }^{16} \mathrm{The} \mathrm{CD}^{\mathrm{C}} 1 \mathrm{~b}^{+} \mathrm{Gr}{ }^{\text {int }}$ cells have considerable similarity to MDSCs, including the expression of CD80. Given that the $\mathrm{Gr} 1{ }^{\text {int }}$ cells resembled MDSCs, we also examined nitric oxide (NO) production by the cells and, as shown in Figure 2d, the cells produced NO that was more than that produced by cDCs. For convenience, from here on we have referred to the LPS-induced myeloid cells as $\mathrm{CD} 11 \mathrm{~b}^{+} \mathrm{Gr} \mathrm{l}^{\text {int }}$ to distinguish them from neutrophils that are $\mathrm{CD} 11 \mathrm{~b}^{+} \mathrm{Gr} \mathrm{h}^{\text {hi }}$ and lung cDCs in which this phenotype has not been encountered. 
Lineage ${ }^{\text {neg }}$ progenitors develop into $\mathrm{CD} 11 \mathrm{~b}+\mathrm{Gr} 1^{\text {int }}$ cells in the lung in the presence of LPS but do not migrate to draining LNs A previous study showed that migratory hematopoietic stem and progenitor cells (HSPCs) proliferate within extramedullary tissues such as the lungs and kidneys in response to LPS and give rise to myeloid cells that express CD11c with a subset also expressing Gr1 at intermediate levels. ${ }^{7}$ It was suggested that an important function of the migratory HSPCs is rapid expansion into innate cells of the immune system after sensing danger signals such as TLR agonists, so that an aggressive immune response can be expeditiously mounted against the invading pathogen. ${ }^{7}$ We, therefore, wished to determine whether infusion
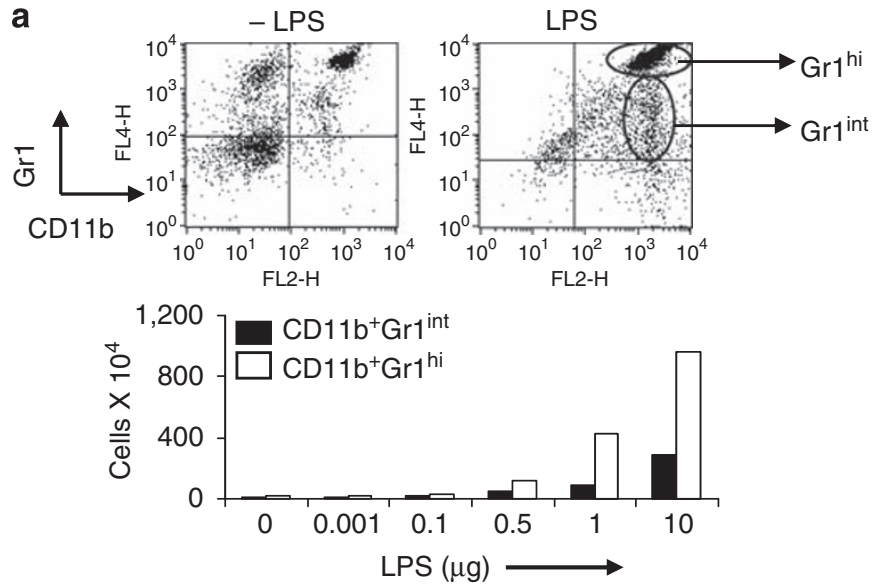

b

Pre-sort
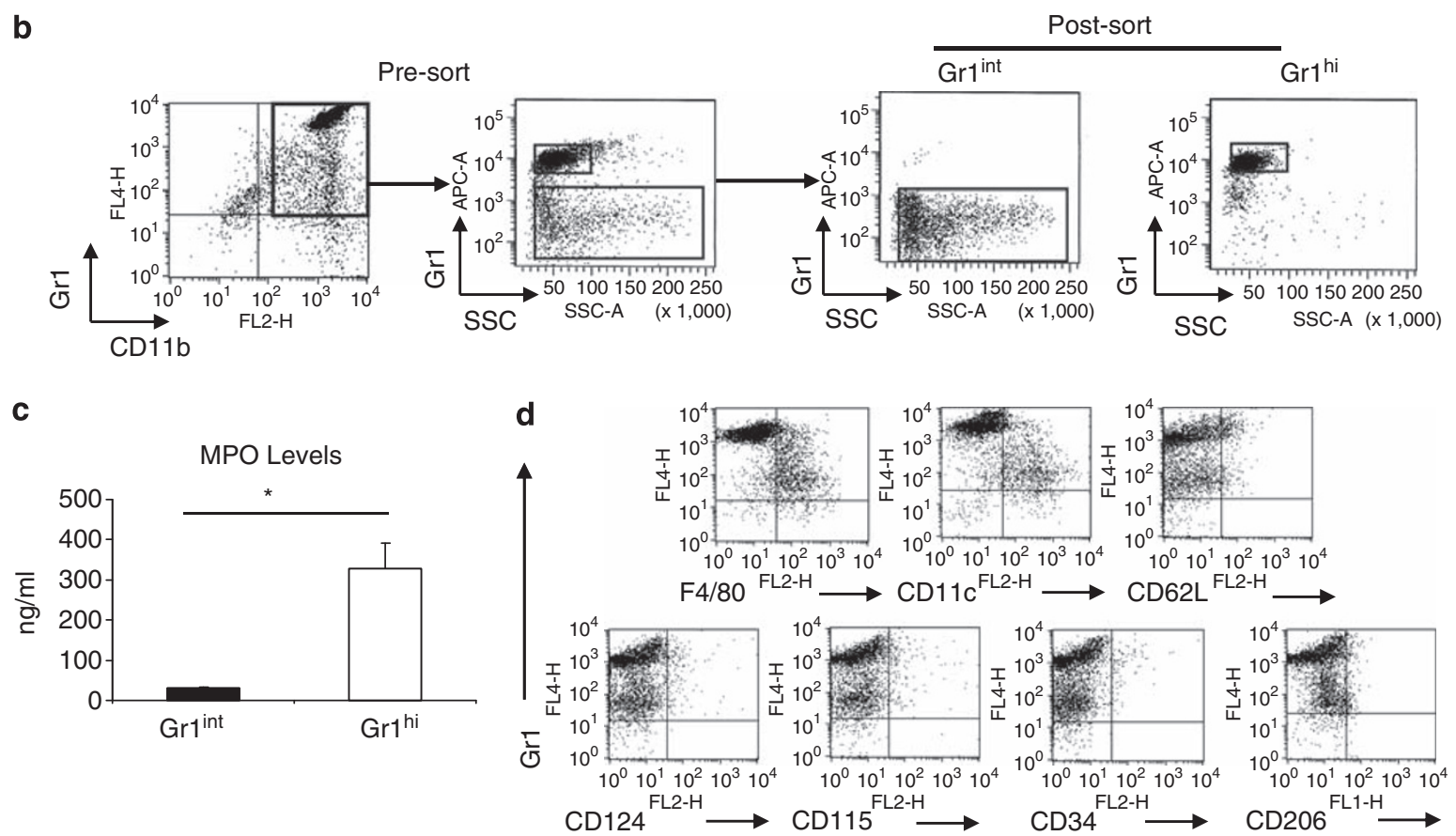

Figure 1 Lipopolysaccharide (LPS) administration increases the frequency of $\mathrm{CD} 11 \mathrm{~b}+\mathrm{Gr} 1^{+} \mathrm{F} 4 / 80^{+}$cells in the lung. Lung cells were isolated by enzymatic digestion of lung tissue. The cells were stained with anti-CD11b and anti-Gr1 monoclonal antibodies and were analyzed by flow cytometry. The forward vs. side light scatter pattern revealed a distinct non-lymphocytic population of cells in which CD11b-expressing and Gr1-expressing cells were concentrated (data not shown). This population of cells was gated upon for subsequent analyses. (a) Expression of CD11b and Gr1 on lung cells measured by flow cytometry with or without LPS treatment of mice (upper panels). The numbers of CD $11 b^{+}$cells expressing high (hi) or intermediate (int) levels of Gr1 were determined in response to increasing concentrations of LPS per treatment (lower panel). (b) Two populations of CD11 $b^{+}$cells from the lungs of LPS-treated mice were sorted based upon expression of intermediate ( $\left.G r^{1}{ }^{\text {int }}\right)$ or high ( $\mathrm{Gr} 1^{\text {hi }}$ ) levels of $\mathrm{Gr} 1$. The purity of $\mathrm{Gr}{ }^{\text {int }}$ and $\mathrm{Gr}{ }^{\text {hi }}$ populations was $>95 \%$. (c) Levels of myleoperoxidase (MPO) in the supernatants of $\mathrm{Gr}^{\text {int }}$ and $\mathrm{Gr}^{\text {hi }}$ populations were detected using an enzyme-linked immunosorbent assay (ELISA) kit for MPO. ${ }^{\star} P<0.05$. (d) Expression of F4/80, CD11c, CD124, CD115, CD62L, CD34, and CD206 on the LPS-induced $\mathrm{CD} 11 \mathrm{~b}^{+} \mathrm{Gr}{ }^{\text {int }}$ cells by flow cytometry. Cursors are placed based on staining with isotype control antibodies. (e) CD11b+ cells isolated from the lungs of LPS-treated mice were sorted based upon expression of Gr1 and F4/80 (upper panels). The purity of CD11 $b^{+} \mathrm{Gr} 1^{\text {int }} \mathrm{F} 4 / 80^{+}$and CD11 $\mathrm{b}^{+} \mathrm{Gr} 1^{\mathrm{hi}} \mathrm{F} 4 / 80^{-}$ cells was $>94 \%$. Cytospin slides were prepared and stained using the three-step stain kit (Richard-Allan Scientific, Waltham, MA). CD11b ${ }^{+} / \mathrm{Gr}^{\mathrm{h}}{ }^{\mathrm{h}} / \mathrm{F} 4 / 80^{-}$

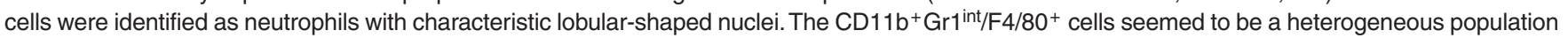
with the majority containing ring-shaped nuclei (inset) (lower panels). The data are representative of at least three independent experiments. 


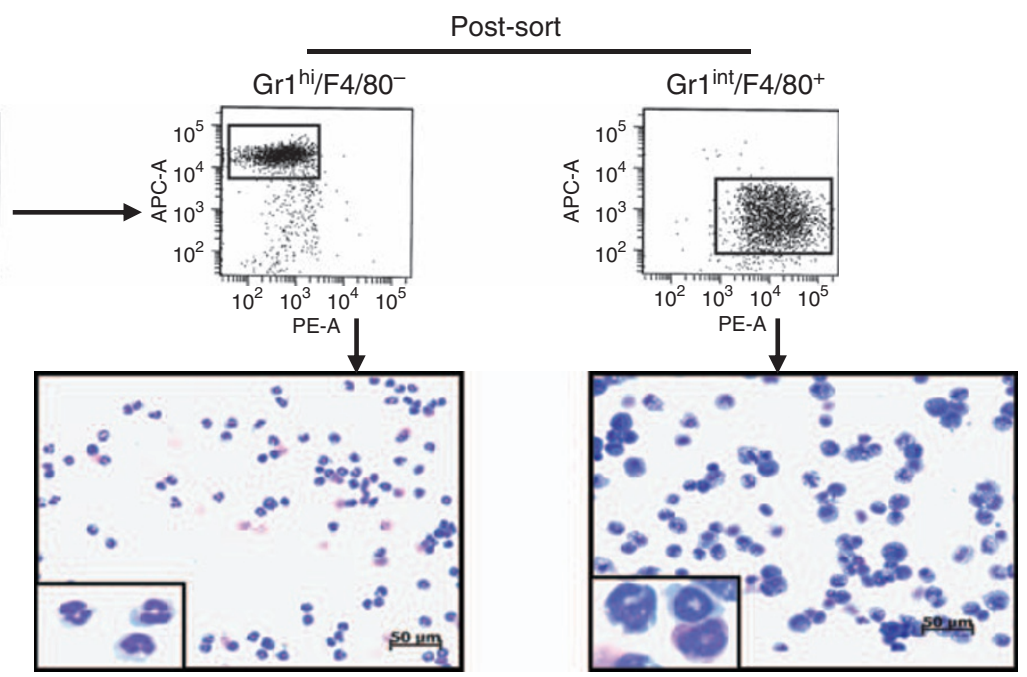

Figure 1 Continued.

of $\mathrm{GFP}^{+}$lineage $\mathrm{n}^{\text {neg }}\left(\mathrm{lin}^{-}\right)$bone marrow progenitor cells into naive mice and subsequent LPS instillation into lungs would promote the development of $\mathrm{GFP}^{+} \mathrm{CD} 11 \mathrm{~b}^{+} \mathrm{Gr} 1^{\text {int }}$ cells. Figure 3a (left panel) depicts the quality of lin $^{-}$cells isolated from bone marrow progenitor cells that express high levels of c-kit but low levels of Gr1 unlike the lin $^{+}$fraction. As shown in Figure 3a (right panel), after intravenous injection of the $\mathrm{lin}^{-} \mathrm{GFP}^{+}$cells, tenfold more $\mathrm{GFP}^{+} \mathrm{CD} 1 \mathrm{~b}^{+} \mathrm{Gr} 1^{\text {int }}$ cells were detected in the lungs of LPStreated mice compared with that in the lungs of control mice.

The earlier study also showed that the HSPCs lack CCR7 and do not migrate to LN draining tissues. ${ }^{7}$ To further determine the similarity of the previously described HSPC-derived cells, we also stained cells with anti-CCR7. The $\mathrm{CD} 11 \mathrm{~b}^{+} \mathrm{Gr} 1^{\text {int }}$ cells isolated from the lung were all largely $\mathrm{CCR}^{-}$, whereas $\mathrm{CD} 11 \mathrm{c}^{+} \mathrm{CCR}^{+}$ cells were detected in the lung (Figure $3 \mathbf{b}$ ). CD11b ${ }^{+} \mathrm{Gr} 1^{\text {int }}$ cells were not detectable in the LNs of the LPS-treated mice (Figure 3c). However, as expected, we observed an $~ 30$-fold increase in the number of DCs in the LN upon LPS treatment (Figure 3c). Given that these data showed that the $\mathrm{CD} 11 \mathrm{~b}{ }^{+} \mathrm{Gr} 1^{\text {int }}$ cells do not traffic to the lung-draining LNs, we reasoned that effects on CD4 ${ }^{+} \mathrm{T}$ cells in the LNs such as proliferation would not be any different in LPS-treated mice when compared with that in the LNs of control mice. Indeed, LPS administration into the lungs of mice did not cause inhibition of proliferation of $\mathrm{CD} 4^{+} \mathrm{T}$ cells in LNs as studied by transfer of carboxyfluorescein succinimidyl ester (CFSE)-labeled naive CD4 ${ }^{+}$T cells and assessment of CFSE dilution in proliferating cells (Figure $3 \mathbf{d}$ ).

\section{High LPS dose blunts allergen-induced allergic airway inflammation and Th2 effector function in the lung}

As our experiments suggested that the LPS-induced CD $11 b^{+} \mathrm{Gr} 1^{\text {int }}$ cells did not traffic to the lung-draining LNs, as was also observed in the previous study, ${ }^{7}$ our next question was whether these cells would temper effector T-cell responses in the tissue. We chose a mouse model of allergic airway inflammation induced by the common household allergen, house dust mite (HDM) (Figure 4a). Mice were sensitized and challenged with $\mathrm{HDM}^{17}$ After one instillation of HDM and allowing time for priming, we assessed IL- $5^{+}$CD $4^{+} \mathrm{T}$ cells by enzyme-linked immunosorbent spot (ELISPOT) assay in the lung-draining LNs. As shown in Figure $\mathbf{4 b}$, significantly greater numbers of IL $-5^{+} \mathrm{CD} 4{ }^{+} \mathrm{T}$ cells were discernible in the LNs of both HDM and HDM + LPS groups when compared with that in the LNs of naive mice, again showing that a high dose of LPS had minimal effects at the LN level. The slightly lower numbers of IL- $5^{+}$cells under conditions of HDM + LPS should be considered in light of the fact that activated $\mathrm{T}$ cells can enter LNs from tissues through afferent lymphatics. ${ }^{18}$ Thus, the number of effector T cells in the draining LNs after immunization is governed by two criteria-cells that remain in the LN and those that migrate to the antigen-delivery site and re-enter the LN through the afferent lymph. As all of our evidence indicated that the $\mathrm{CD} 11 \mathrm{~b}^{+} \mathrm{Gr} 1^{\text {int }}$ cells develop in the lung without detectable presence in the LNs, we did not expect to see any influence on effector response in the LNs soon after priming, which is what we observed. However, when the lungs were examined after three rounds of challenges with the allergen alone or in the presence of LPS, a significant reduction in airway inflammation as well as Th2 cytokine levels in the lung was observed when LPS was mixed with HDM (Figure 4c and d). Thus, LPS treatment induced a condition in the lung that did not favor effector Th2 responses. Most importantly, LPS did not cause more interferon $-\gamma$ production in the lung, suggesting that the inhibition was not due to cross-regulation by this cytokine. If our inference was correct that the LPSinduced tissue-dwelling myeloid cells would suppress Th2 effector function in the lung, we expected in vitro-generated Th2 cells to be unable to induce inflammation in the airways of LPS-treated mice. To test this, Th2 cells were generated in vitro by repetitive stimulation of $\mathrm{CD}^{+}{ }^{+}$(DO11.10) T cells under Th2-skewing conditions. The cells were then adoptively transferred into control and LPS-treated mice and the cells were recruited to the lung by challenge with aerosolized ovalbumin (OVA). ${ }^{19,20}$ There was a remarkable difference in the level of airway inflammation between the LPS-treated and untreated groups, with severe inhibition observed when cells were transferred into LPS-treated mice (Figure 4e). 
This observation was in line with a previous report in which intravenous LPS administration was shown to suppress experimental asthma in a nitric oxide synthase 2 (NOS2)-dependent manner, although the mechanism for this observation was not identified. ${ }^{9}$

\section{LPS-induced development of CD11b+Gr1 $1^{\text {int }}$ cells is dependent on MyD88 but not TRIF and inhibition of eosinophilic inflammation by LPS is abolished without MyD88}

Our next aim was to determine which of the TLR4-induced pathways, myeloid differentiation factor 88 (MyD88) dependent or
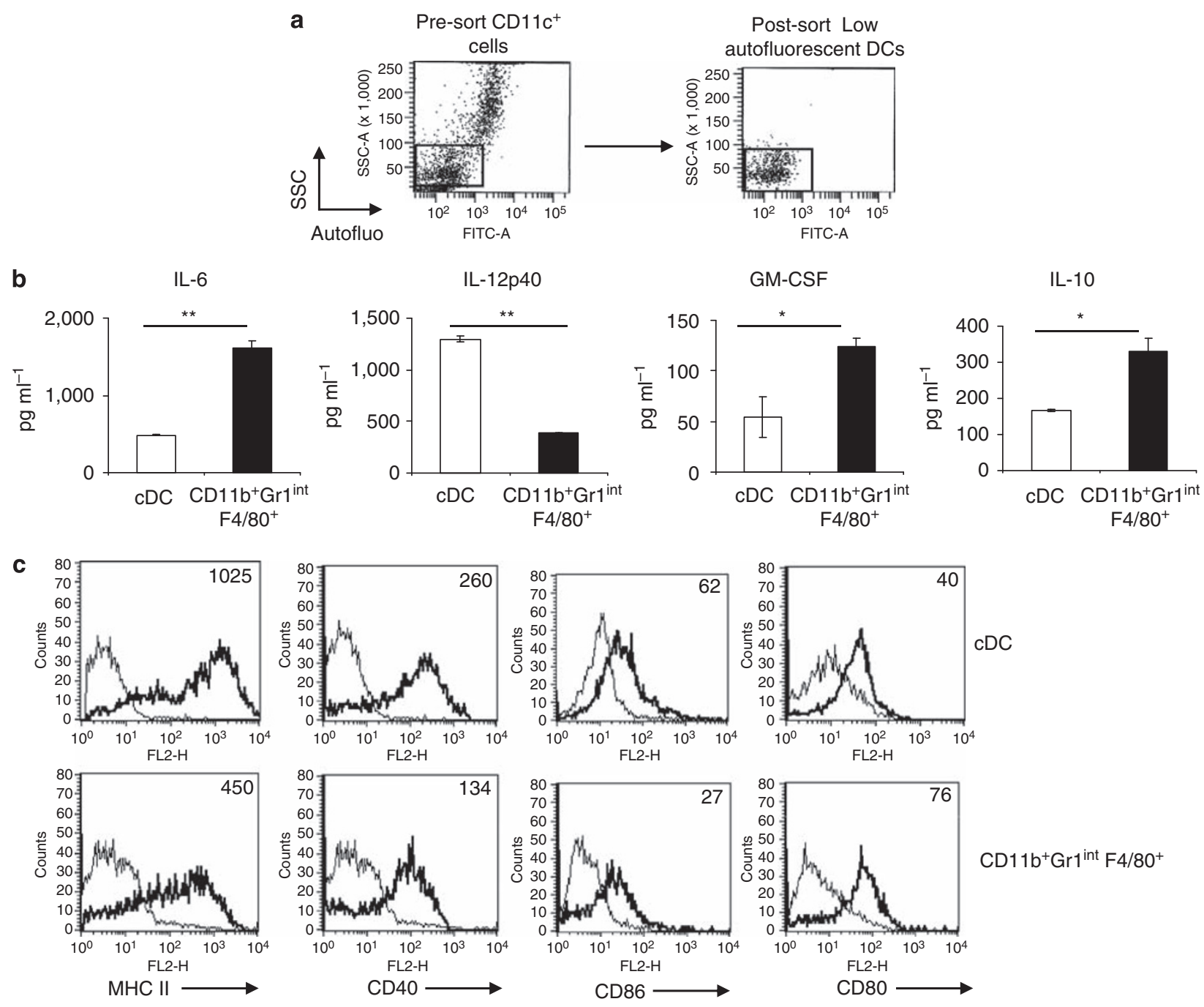

d

NO Levels

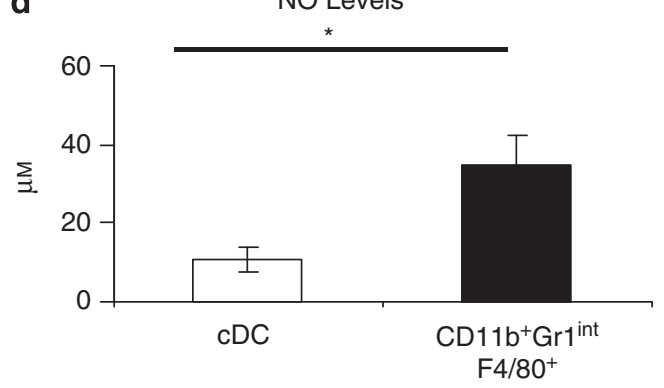

Figure $2 \mathrm{CD} 11 \mathrm{~b}+\mathrm{Gr} 1^{\text {int }} \mathrm{F} 4 / 80^{+}$cells induced by lipopolysaccharide (LPS) administration are distinct from conventional lung dendritic cells (DCs). (a) $\mathrm{CD} 11 \mathrm{c}^{+}$cells were purified from the lung cells obtained from LPS-treated mice. Conventional DCs (cDCs) were identified as CD11 $\mathrm{c}^{+}$cells with a relatively low level of autofluorescence and side scatter and were used as APCs in experiments where needed. The purity of these cells was $>95 \%$. (b) $2 \times 10^{5}$ cells ( $\mathrm{CDCs}$ or $\mathrm{CD} 11 \mathrm{~b}+\mathrm{Gr} 1^{\text {int }} \mathrm{F} 4 / 80^{+} \mathrm{cells}$ ) were plated for $20 \mathrm{~h}$ and culture supernatants were analyzed for cytokine production. Values shown are mean \pm s.e.m., ${ }^{*} P<0.01,{ }^{* \star} P<0.001$. (c) Expression of co-stimulatory molecules detected by flow cytometry on the $\mathrm{CDC}$ and $\mathrm{CD} 11 \mathrm{~b}+\mathrm{Gr}{ }^{\mathrm{int}}$ $\mathrm{F} 4 / 80+$ populations. Dark lines represent expression of the indicated molecules, the light lines being background fluorescence determined by staining with appropriate isotype control antibodies. (d) Levels of nitric oxide (NO) in the supernatants of cell cultures. DC and $\mathrm{Gr} 1^{\text {int }} / \mathrm{F} 4 / 80^{+}$were isolated from the same LPS-treated mice as described before. Data shown are representative of two independent experiments and depict mean \pm S.d. ${ }^{*} P<0.05$. 
independent (through TIR-domain-containing adapter-inducing interferon- $\beta$ (TRIF)), was responsible for the generation of our cell of interest. To match their genetically altered counterparts, wild-type (WT) control mice used for the MyD88 ${ }^{-/-}$mice were on Balb/c background, whereas those for the TRIF ${ }^{-1-}$ animals were on C57BL/ 6 background. We were able to generate the
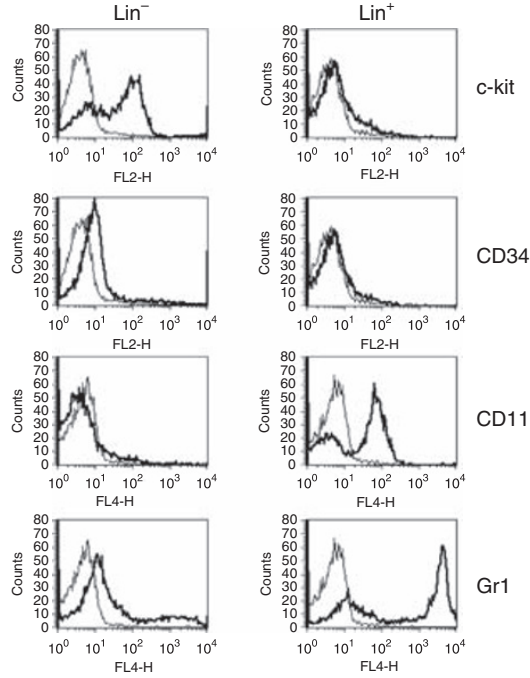
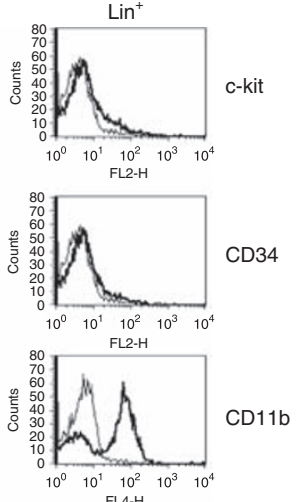

b

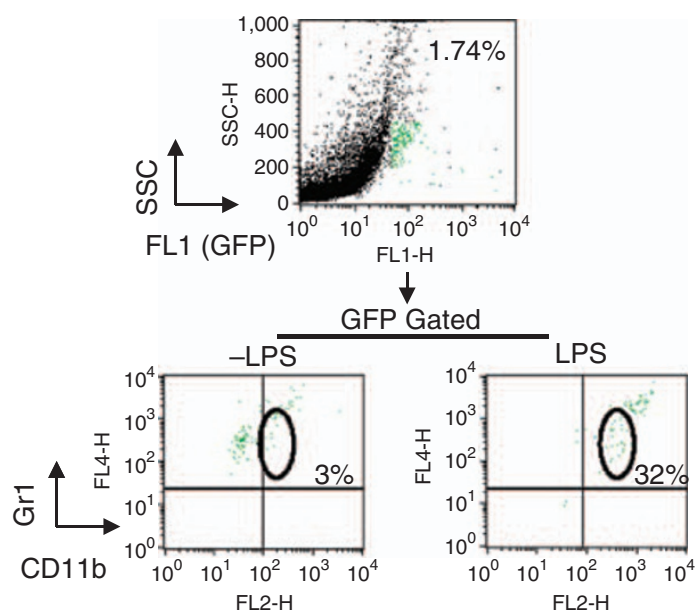

Lung
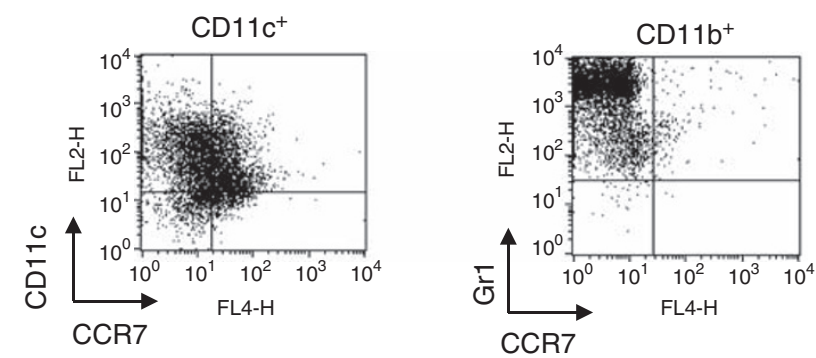

c

LN
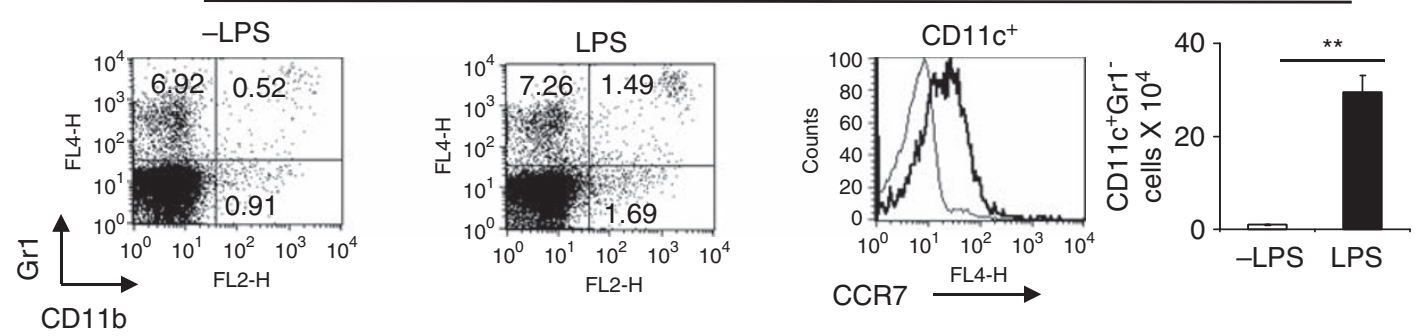

Figure 3 The $C D 11 b+G r 1^{\text {int }}$ cells do not migrate to the lung-draining lymph nodes (LNs) and lipopolysaccharide (LPS) instillation in the lung does not inhibit CD4 ${ }^{+}$T-cell proliferation in the LNs. (a) The lin- population in bone marrow cells was enriched using a lineage depletion kit and phenotypic analysis was performed by flow cytometry. In addition, shown is the phenotypic analysis of the lin ${ }^{+}$fraction. The lin- population of bone marrow cells was enriched from enhanced green fluorescent protein (EGFP) transgenic mice and transferred intravenously (i.v.) into naive mice. Mice were divided into two groups and one group then received three daily treatments of $10 \mu \mathrm{g}$ LPS, whereas the other group was left untreated. The top right panel shows the presence of GFP ${ }^{+}$cells in the lung after transfer of $\mathrm{GFP}^{+}$lin $^{-}$cells. The forward vs. side light scatter pattern revealed a distinct non-lymphocytic population of cells in which CD11b-and Gr1-expressing cells were concentrated (data not shown). This population of cells was gated on for subsequent analyses. Within the GFP gate, the percentage of cells expressing intermediate (int) levels of Gr1 was determined in the presence or absence of LPS (lower panel). (b) CD11 ${ }^{+}$and CD11 b cells were purified from the lung cells obtained from LPS-treated mice. Expression of CCR7 on low autofluorescent CD11 $\mathrm{c}^{+}$and CD11 $\mathrm{b}^{+}$cells was detected by flow cytometry. (c) Expression of CD11b and Gr1 on LN cells measured by flow cytometry with or without LPS treatment of mice. The histogram shows CCR7 levels on $\mathrm{CD} 11 \mathrm{c}^{+}$cells obtained from LN cells of LPS-treated mice. Thin gray lines indicate staining with appropriate isotype control antibody and the overlay represents expression of the CCR7 molecules. The last panel shows a $\sim 30$-fold increase in the number of CD11c ${ }^{+} \mathrm{Gr} 1^{-}$cells in the LNs in LPS-treated mice. Data represent average values obtained from three independent experiments \pm s.d. ${ }^{\star \star} P<0.005$. (d) T cell receptor $(\mathrm{TCR})$ transgenic CD4 ${ }^{+} T$ cells were isolated from the spleens of DO11.10 mice. The cells were labeled with carboxyfluorescein succinimidyl ester (CFSE) and adoptively transferred to either naive or LPStreated mice (four daily treatments with $10 \mu \mathrm{g}$ per treatment of LPS). Beginning 1 day after adoptive transfer, the mice received ovalbumin/cholera toxin (OVA/ CT) once per day for 2 days. After $24 \mathrm{~h}$, the number of $\mathrm{KJ}-126^{+}$(DO11.10), CFSE-expressing cells in the lung-draining LNs was determined (upper panel), and the degree of cell proliferation was quantitated based upon CFSE dilution (lower panels). Results shown are representative of two independent experiments.

Figure 3 Continued on the following page 
d
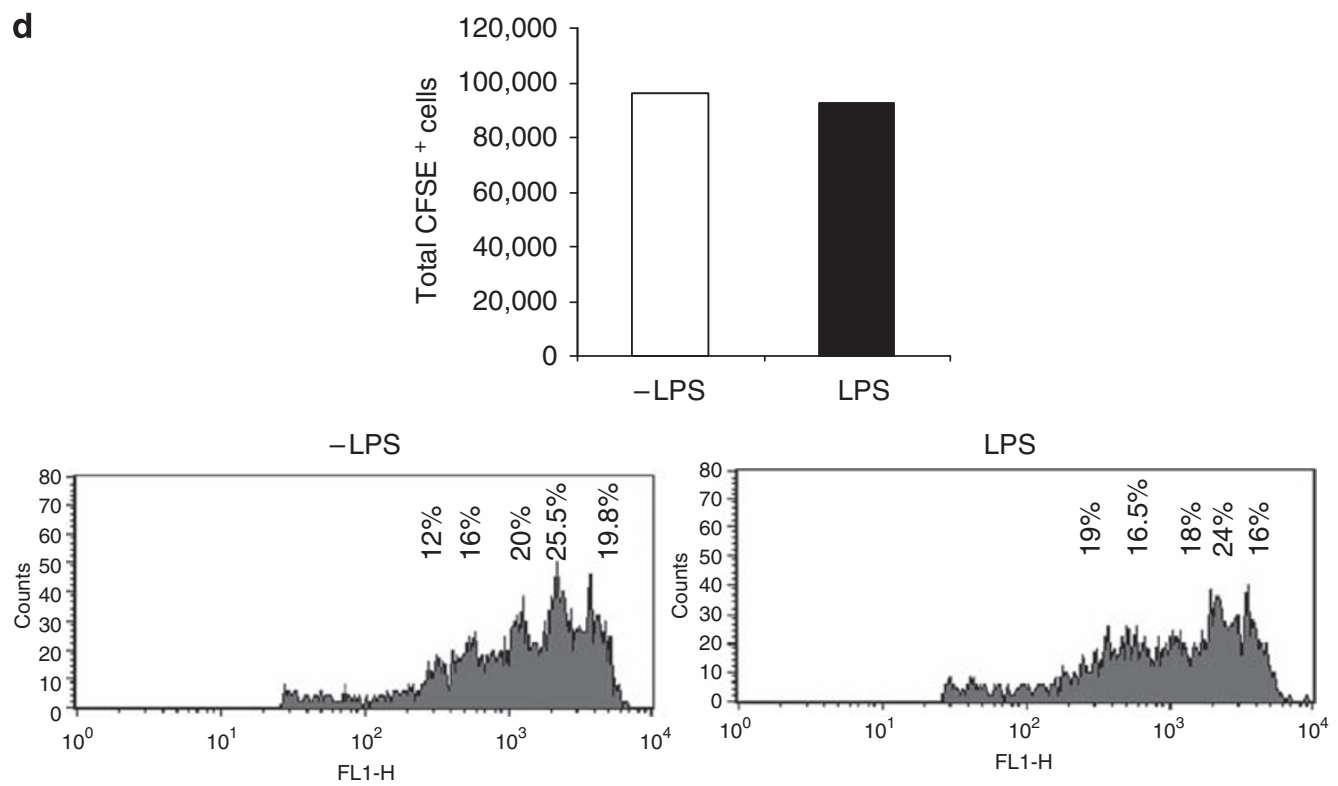

Figure 3 Continued.

$\mathrm{CD} 11 \mathrm{~b}^{+} \mathrm{Gr} 1^{+}$cells in the presence of GM-CSF + LPS but not with either agent alone from $\mathrm{lin}^{-}$bone marrow progenitor cells (Supplementary Figure S2 online). GM-CSF alone induced DC development as is standard for generation of bone marrowderived DCs from mouse cells. No difference in the generation of the $\mathrm{CD} 11 \mathrm{~b}^{+} \mathrm{Gr} 1^{\text {int }}$ cells has been noted by us, irrespective of whether bone marrow cells were derived from Balb/c or C57BL/6 mice. Cells developed under both conditions expressed the myeloid marker CD11b. In contrast to $80-90 \%$ of the cells generated in the presence of GM-CSF being conventional CD11c+ DCs, simultaneous stimulation with LPS reduced CD11 $\mathrm{c}^{+}$cells to $<5 \%$

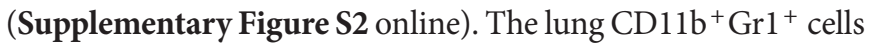
were found to express CD11c (Figure 1d), but at a lower level compared with expression by lung cDCs. The GM-CSF + LPSinduced cells also expressed Gr1 and Thy1.2, the latter being only found on the in vitro-generated cells. Interestingly, Thy1.2 expression on a minor subset of splenic CPG oligodeoxynucleotideinduced CD11 $\mathrm{c}^{+}$DCs was previously described. ${ }^{21} \mathrm{MyD} 88$, but not TRIF, deficiency blocked generation of $\mathrm{Gr}^{+}$cells from bone marrow cells in the presence of GM-CSF and LPS (Figure 5a). To further strengthen this observation, we took a complementary approach of culturing bone marrow cells with GM-CSF and poly (I:C), a TLR3 ligand that only signals through TRIF. Unlike LPS, different doses of poly (I:C) when combined with GM-CSF did not induce generation of the $\mathrm{CD} 11 \mathrm{~b}^{+} \mathrm{Gr} 1^{\text {int }}$ cells (data not shown). To determine the role of MyD88 in vivo, TLR4 ${ }^{-1-}$ and MyD88 ${ }^{-/-}$mice were treated with LPS and the frequency of the $\mathrm{CD} 11 \mathrm{~b}^{+} \mathrm{Gr} 1^{\text {int }}$ cells in their lungs was compared with that in untreated mice. As shown in Figure 5b, the $\mathrm{CD} 11 \mathrm{~b}^{+} \mathrm{Gr} 1^{\text {int }}$

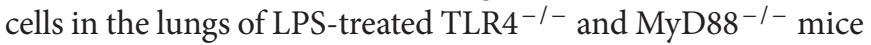
increased by only $\sim 8$ - and 4 -fold, respectively, when compared with 63-fold in WT mice.

To functionally ascertain the influence of LPS on HDMinduced allergic responses in the absence of MyD88, WT and MyD88 ${ }^{-/-}$mice were sensitized and challenged with HDM in the presence or absence of LPS. Interestingly, the MyD88 ${ }^{-1-}$ mice showed attenuated airway inflammation compared with WT mice in response to HDM (please compare with inflammatory response in WT mice as shown in Figure 4). Recently, Der p 2 (Dermatophagoides pteronyssinus group 2), a key allergen of HDM, was shown to be a mimic of the TLR4-associated adaptor MD-2 and provide this essential component of LPS-induced TLR4 signaling in lung epithelial cells that lack MD-2. ${ }^{22}$ Similarly, TLR4 signaling in epithelial cells was shown to be important for HDM-induced allergic airways disease. ${ }^{23}$ In line with these observations, the MyD88 ${ }^{-/-}$mice mounted less airway inflammatory response, although it was not totally absent (Figure 5c). Interestingly, almost twice the number of cells could be recovered in the bronchoalveolar lavage (BAL) fluid when LPS was administered together with HDM in the MyD88-deficient mice compared with that obtained with HDM alone (Figure 5c). The results of these experiments showed that the absence of MyD88 abolishes the suppressive function of a high dose of LPS. However, given that the TRIF/type I interferon pathway stimulates the expression of costimulatory molecules, ${ }^{24}$ it is likely that LPS augmented HDM-induced airway inflammation in MyD88 $8^{-1-}$ mice not only because of a reduction in the number of $\mathrm{CD} 11 \mathrm{~b}^{+} \mathrm{Gr} 1^{\text {int }}$ cells in the absence of MyD88 but also because of preservation of the second pathway, TRIF, downstream of TLR4. Along with increased eosinophilic airway inflammation, the HDM/LPS combination also yielded more IL5 in the lung when compared with treatment with HDM alone (Figure 5c).

\section{Activation of Th2-primed cells by lung DCs is inhibited by CD11b + Gr $1^{\text {int }}$ cells with effects on STAT5 phosphorylation and GATA-3 expression}

We next sought to determine whether the $\mathrm{CD} 11 \mathrm{~b}^{+} \mathrm{Gr} \mathrm{1}^{\text {int }}$ cells could block activation of transcription factors such as STAT5 and GATA- 3 in freshly primed Th2 cells. GATA- 3 is the key 
regulator of Th2 differentiation, as previously described by us and others, ${ }^{25-29}$ and a role for STAT5 in Th2 differentiation has also been shown. ${ }^{30,31}$ The protocol of priming involving 6 days of culture under Th2-skewing conditions does induce GATA-3, although at low levels in a small fraction of the $\mathrm{CD} 4^{+} \mathrm{T}$ cells, as judged by expression of GATA-3-dependent genes such as T1ST2. ${ }^{31}$ Administration of anti-T1ST2 into mice blocks the effector function of adoptively transferred OVA-specific Th2 cells, including Th2 cytokine secretion and eosinophilic airway inflammation. The expression of T1ST2 has been recently

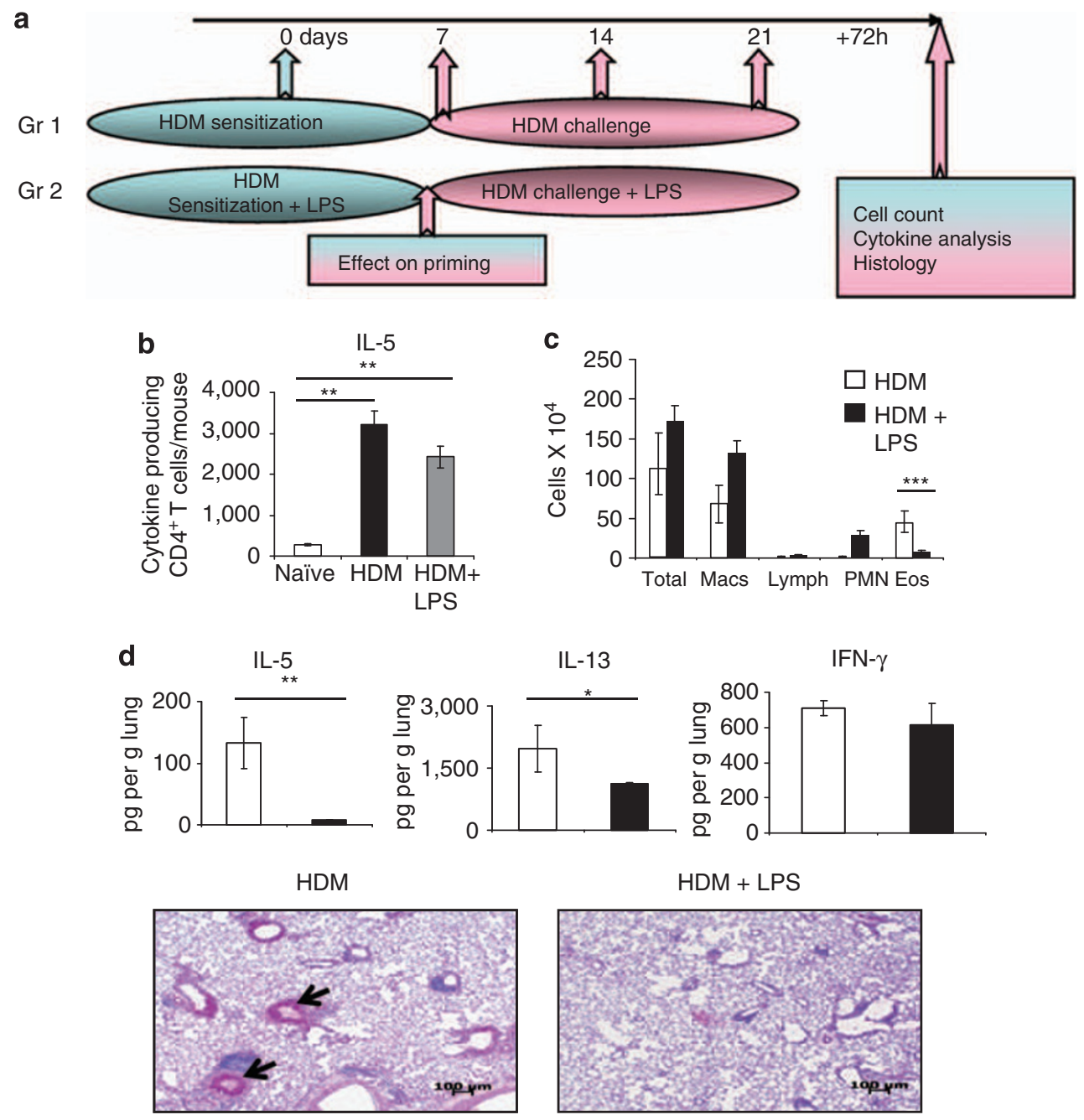

Figure 4 Suppression of house dust mite (HDM)- and T-helper 2 (Th2) cell-induced eosinophilic inflammation in the airways by lipopolysaccharide (LPS). (a) Diagram of the treatment protocol. HDM (100 $\mu$ g per mouse) \pm LPS (10 $\mu$ LPS per mouse) was administered intratracheally (i.t.) at the indicated time points. Lung-draining lymph nodes (LNs) were harvested from one group 7 days after one HDM instillation \pm LPS to assess CD4 ${ }^{+} T-$ cell priming. The rest of the animals were challenged with HDM \pm LPS and at $72 \mathrm{~h}$ after the final instillation, bronchoalveolar lavage (BAL) fluid and lung tissue samples were obtained. (b) Enzyme-linked immunosorbent spot (ELISPOT) assay of cells harvested from lung-draining LNs. Naive mice were used as control. For all the groups, the total cell population was used for ELISPOT assay and the number of cytokine-expressing Th cells was estimated based upon the percentage of CD4 ${ }^{+} \mathrm{T}$ cells determined by flow cytometry. For the HDM and HDM + LPS groups, CD4 ${ }^{+} \mathrm{T}$ cells were also purified by magnetic bead selection before being subjected to the assay to confirm that the cytokines were being produced by CD4 ${ }^{+} \mathrm{T}$ cells. In all cases, cells were stimulated for 8-10 h with phorbol-12-myristate-13-acetate (PMA; $25 \mathrm{ng} \mathrm{ml}^{-1}$ ) plus ionomycin $\left(500 \mathrm{ng} \mathrm{ml}^{-1}\right)$. Results are expressed as the number of cytokine-producing cells per sample. Data shown are mean \pm s.d. ${ }^{\star \star} P<0.01$. The data shown are representative of two independent experiments. (c) Counts of cells recovered in the BAL fluid. Values are mean +s.e.m. ${ }^{* \star *} P<0.005$. (d) The concentrations of interleukin (IL)-5, IL13 , and interferon- $\gamma(\mathrm{IFN}-\gamma)$ in lung homogenates were measured by multiplex assay and are presented as mean \pm s.e.m. ${ }^{\star} P<0.05$ and ${ }^{* *} P<0.01$. Histological examination of lung sections stained with periodic acid-Schiff (PAS) for assessment of inflammation and mucus production. Lung infiltrates around bronchovascular bundles in which eosinophilic response is most pronounced in disease were of +4 grade in animals that received HDM and $+1 / 2$ in those that received LPS together with HDM. Arrows indicate mucus staining. The data shown are representative of three independent experiments. (e) T-helper 2 (Th2) cells were generated in vitro using CD4 ${ }^{+}$T cells from DO11.10 mice and were injected i.v. into either LPS-treated mice or naive recipient mice $\left(5 \times 10^{6}\right.$ cells per mouse). The mice were then exposed to aerosolized ovalbumin (OVA) daily for 7 days and were analyzed $24 \mathrm{~h}$ after the last exposure. Total and differential counts of cells recovered in the BAL fluid (upper panel) and hematoxylin and eosin (H\&E) staining of lung sections (lower panels) of both groups of mice were performed. Values are mean \pm s.e.m. ${ }^{*} P<0.01$ and ${ }^{* \star} P<0.001$. The data shown are representative of two independent experiments. 

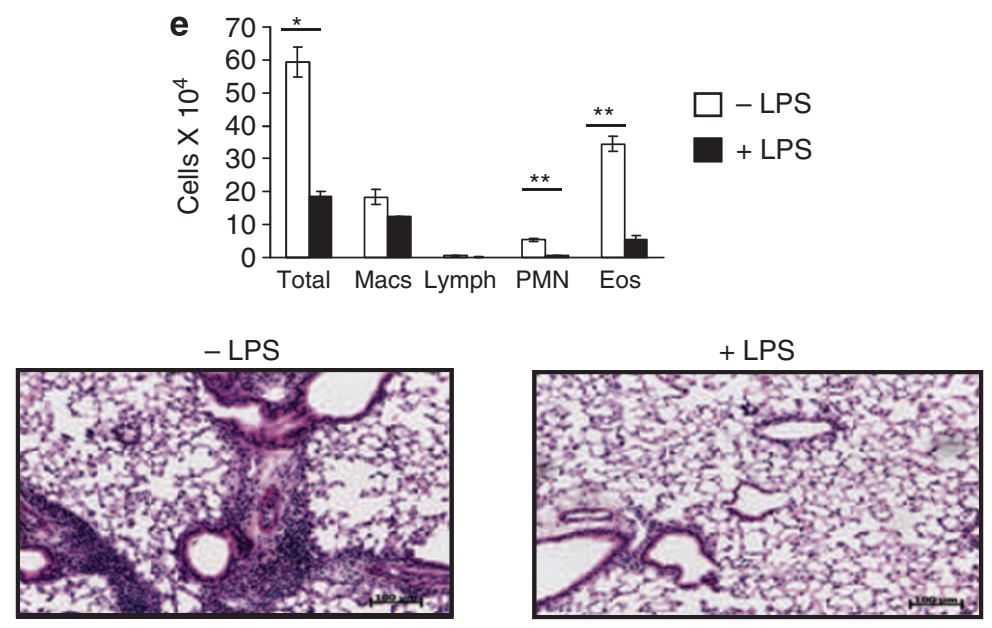

Figure 4 Continued.

shown to require GATA-3 and activated STAT5. ${ }^{31}$ We reasoned that if both STAT5 and GATA-3 are required for expression of Th2 cytokine genes and other Th2 expressed molecules such as T1ST2, the efficient Th2 suppression observed in vivo (Figure 4) might be because of the inability of primed Th2 cells migrating into tissue to be reactivated by tissue DCs, resulting in GATA-3 upregulation and STAT5 activation. We, therefore, asked whether stimulatory effects of lung $\mathrm{cDCs}$ on the primed Th2 cells would be compromised by the LPS-induced lung $\mathrm{CD} 11 \mathrm{~b}^{+} \mathrm{Gr} 1^{\text {int }}$ cells. As measures of Th2 activation, we examined Th2 cytokine production, STAT5 phosphorylation, and GATA-3 expression (Figure 6). The frequency of IL-5-secreting Th2 cells was ascertained by intracellular cytokine staining after coculture of the primed Th2-skewed cells with either lung cDCs, CD $11 b^{+} \mathrm{Gr} 1^{\text {int }}$ cells, or their mixture for $36 \mathrm{~h}$, as shown in Figure 6a. The ratio of DC to CD11b $b^{+} \mathrm{Gr} 1^{\text {int }}$ cells used was 1:5 based on our quantitation of these cells in the lungs after LPS administration over a 4-day time period that ranges from five- to ten-fold more than cDCs. As expected with specific antigen-induced stimulation, and as opposed to phorbol-12myristate-13-acetate plus ionomycin that would activate all primed $\mathrm{T}$ cells, a fraction of $\mathrm{CD} 4$ cells showed blast-like (activated) morphology (by forward scatter vs. side scatter, data not shown) as well as typically lower CD4 expression. ${ }^{32,33}$ Among reactivated CD4 cells (reduced CD4 expression), the frequency of IL-5-secreting cells was greater with stimulation by lung cDCs when compared with lung $\mathrm{CD} 11 \mathrm{~b}^{+} \mathrm{Gr} 1^{\text {int }}$ cells (Figure 6a). In addition, fivefold more $\mathrm{CD} 11 \mathrm{~b}^{+} \mathrm{Gr} 1^{\text {int }}$ cells reduced cytokine production by $55.0 \pm 3.5 \%$. However, as expected, the addition of fivefold more lung cDCs slightly increased cytokine production (data not shown). Furthermore, IL-5 production was inhibited when the $\mathrm{cDC}$ s were mixed with the $\mathrm{CD} 11 \mathrm{~b}^{+} \mathrm{Gr} 1^{\text {int }}$ cells in a 1:5 ratio by $60.7 \pm 2.4 \%$ (Figure $6 a$ ). The inhibition was not reversed when the NOS2 inhibitor L-(1-iminoethyl)lysine (L-NIL) was used. We next cocultured the primed Th2 cells with cDCs or $\mathrm{CD} 11 \mathrm{~b}^{+} \mathrm{Gr} 1^{\text {int }}$ cells as above, removed the culture supernatant, and exposed the cells briefly to IL-2 to assess STAT5 phosphorylation. IL-2 was able to induce STAT5 phosphorylation in cells cocultured with lung DCs and same numbers of $C D 11 b^{+} \mathrm{Gr} 1^{\text {int }}$ cells but not when fivefold more $\mathrm{CD} 11 \mathrm{~b}^{+} \mathrm{Gr} 1^{\text {int }}$ cells were used (Figure 6b). When added to cDCs, the cells partially inhibited STAT5 phosphorylation that was reversed by L-NIL. The reversal of suppression by L-NIL was expected, as NO blocks Jak3-mediated STAT5 activation. ${ }^{34,35}$ With respect to GATA- 3 expression, lung cDCs induced an increase in GATA-3 expression in the primed Th2 cells. Similar to results obtained for STAT5 phosphorylation, equal numbers of $\mathrm{CD} 11 \mathrm{~b}^{+} \mathrm{Gr} 1^{\text {int }}$ cells as $\mathrm{cDCs}$ also caused GATA-3 upregulation. However, at fivefold higher numbers and when mixed with DCs, GATA-3 upregulation was not achieved (Figure 6c). However, it is noteworthy that the cells maintained a low level of GATA-3 expression. Addition of L-NIL only slightly reversed GATA-3 expression (Figure 6c).

Several mediators produced by MDSCs have been shown to mediate their suppressive functions, which include NO, reactive oxygen species, and arginase I (Arg1) $)^{13,36-38}$ Using reverse transcriptasePCR techniques, both Arg1 and NOS2 expression was detected in the $\mathrm{CD} 11 \mathrm{~b}^{+} \mathrm{Gr} 1^{\text {int }}$ cells (data not shown). We therefore examined whether the suppressive effect of the lung-derived $\mathrm{CD} 11 \mathrm{~b}^{+} \mathrm{Gr} 1^{\text {int }}$ cells could be reversed by inhibiting some of these mediators produced by the cells. As shown in Figure 6d, addition of the Arg1 inhibitor, nor- $\mathrm{N}(\omega)$-hydroxy-nor-1-arginine, or use of neutralizing anti-IL-10 antibody completely reversed Th 2 cytokine suppression by the $\mathrm{CD} 11 \mathrm{~b}^{+} \mathrm{Gr} \mathrm{l}^{\text {int }}$ cells. However, addition of apocynin (inhibitor of NADPH oxidase), uric acid (peroxynitrite scavenger), or L-NIL (specific inhibitor of NOS2) to the coculture did not reverse the suppressive effects of $\mathrm{CD} 11 \mathrm{~b}^{+} \mathrm{Gr} 1^{\text {int }}$ cells on $\mathrm{CDC}$-induced IL13 production from primed Th2 cells (Supplementary Figure S3 online). Thus, although L-NIL partially restored the ability of the Th2 cells to mount STAT5 activation and express GATA-3, it was not able to reverse suppression of cytokine production, which was only achieved by blocking Arg1 and IL- 10 .

\section{Adoptive transfer of in vitro- or in vivo-induced $\mathrm{CD} 11 \mathrm{~b}+\mathrm{Gr} 1^{\text {int }}$ cells inhibit allergen-induced airway inflammation}

Because all of our data showed the ability of the $\mathrm{CD} 11 \mathrm{~b}^{+} \mathrm{Gr} \mathrm{1}^{\text {int }}$ cells to inhibit the effector function of Th2 cells, we asked whether under post-allergen-sensitized conditions that would mimic human disease, intratracheally transferred $\mathrm{CD} 11 \mathrm{~b}^{+} \mathrm{Gr} 1^{\text {int }}$ cells 
a
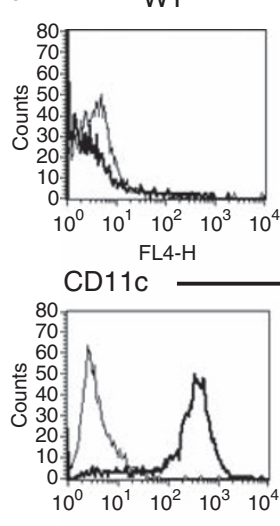

FL2-H CD11b

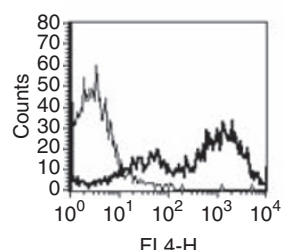

Gr1
${\mathrm{MyD} 88^{-/-}}^{-1}$
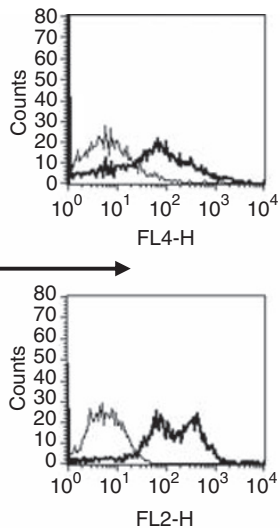

FL2-H

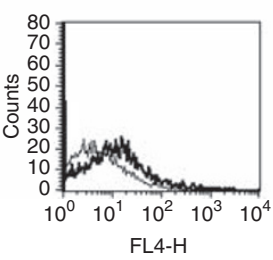

WT

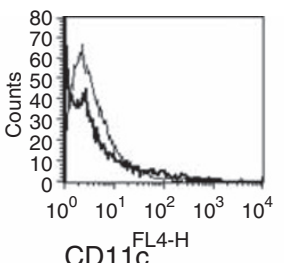

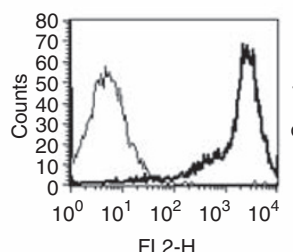

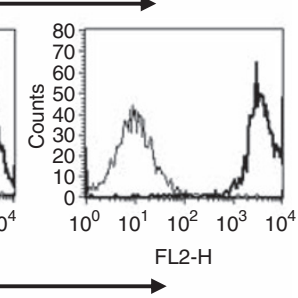

CD11b
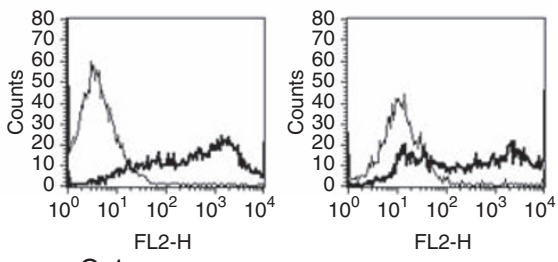

Gr1

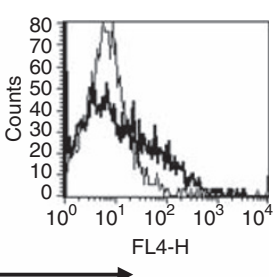

b

\begin{tabular}{|l|c|c|c|}
\hline & No LPS & LPS & Fold Increase \\
\hline WT & $4.9 \times 10^{4}$ & $309 \times 10^{4}$ & 63 \\
\hline TLR4 $^{-/-}$ & $9.5 \times 10^{4}$ & $75 \times 10^{4}$ & 7.97 \\
\hline MyD88 $^{-/-}$ & $9.2 \times 10^{4}$ & $39.1 \times 10^{4}$ & 4.25 \\
\hline
\end{tabular}

c
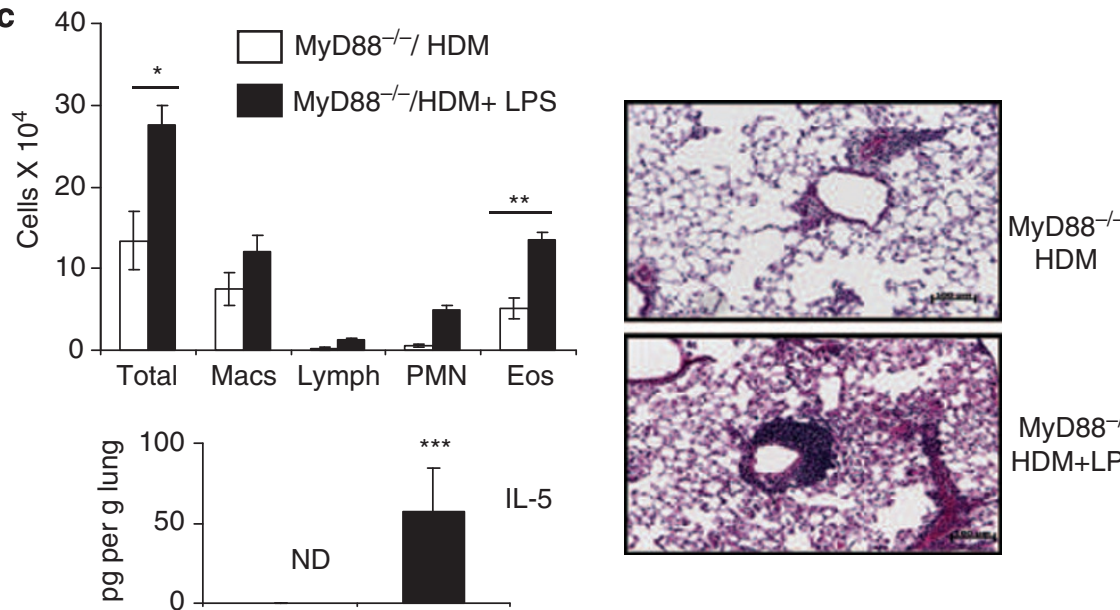

$-5$

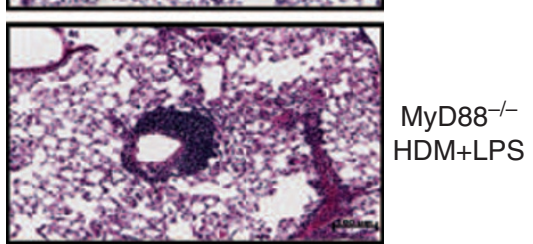

Figure 5 Myeloid differentiation factor 88 (MyD88) dependence on the development of CD11b+Gr $1^{\text {int }}$ cells. (a) Bone marrow cells were cultured with granulocyte-macrophage colony-stimulating factor (GM-CSF) and lipopolysaccharide (LPS) for 9 days and phenotypic analysis was performed using flow cytometry. The resulting cells from wild-type (WT) Balb/c mice were compared with those from MyD88-deficient (MyD88-/-) mice (lefthand panel), and those from WT C57BL/6 mice were compared with TRIF-deficient (TRIF ${ }^{-/-}$) mice (right-hand panel). (b) Estimation of fold induction

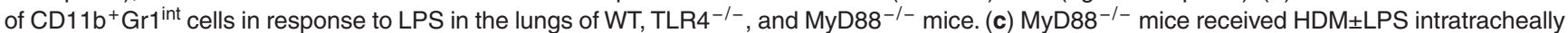
(i.t.) as in Figure 4a. At $72 \mathrm{~h}$ after the final instillation, bronchoalveolar lavage (BAL) fluid and lung tissue samples were obtained. Total and differential counts of cells recovered in the BAL fluid (left-hand panel) and hematoxylin and eosin (H\&E) staining of lung sections (right-hand panels) were performed. Values shown are mean \pm s.d., ${ }^{*} P<0.05$, ${ }^{\star *} P<0.005$. The concentration of interleukin-5 (IL-5) in lung homogenates was measured by multiplex assay and is presented as mean \pm S.e.m. ${ }^{* \star} P<0.001$. The data shown are representative of two independent experiments. 
a
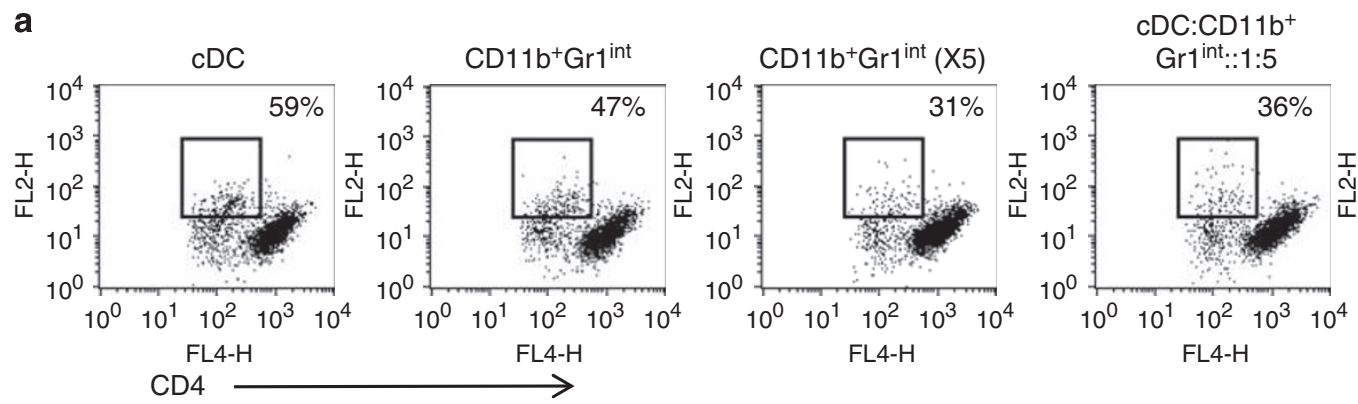

$\mathrm{CDC}: \mathrm{CD} 11 \mathrm{~b}^{+}$

Gr1 ${ }^{\text {int:: }: 1: 5+\text { L-NIL }}$
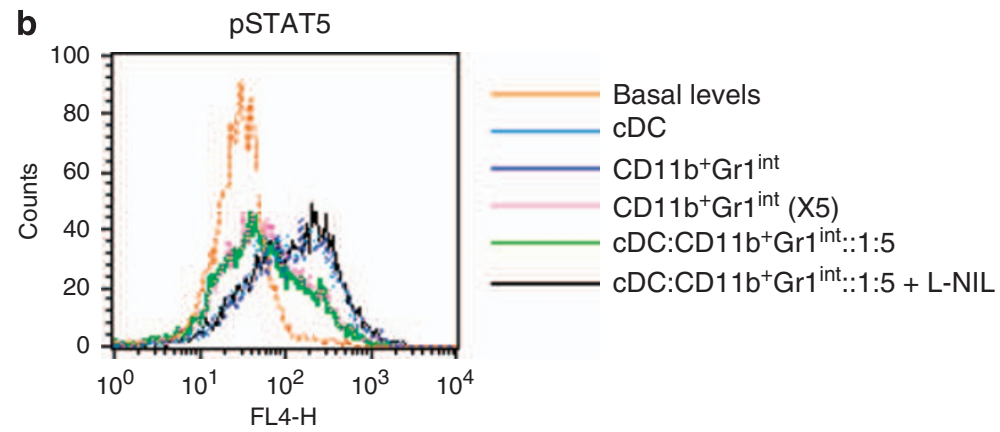

C

Primed Th2 cells

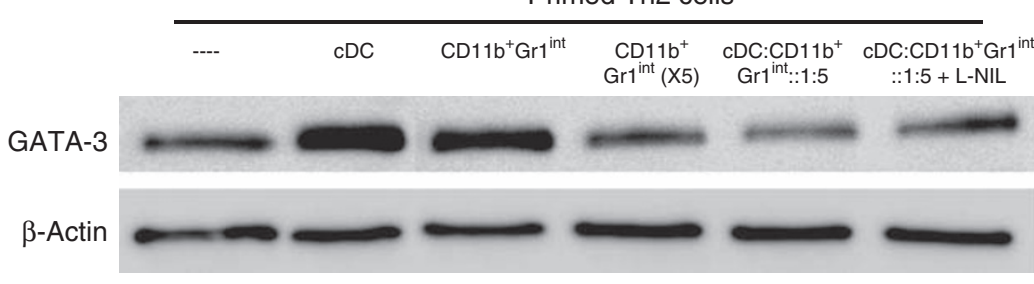

d
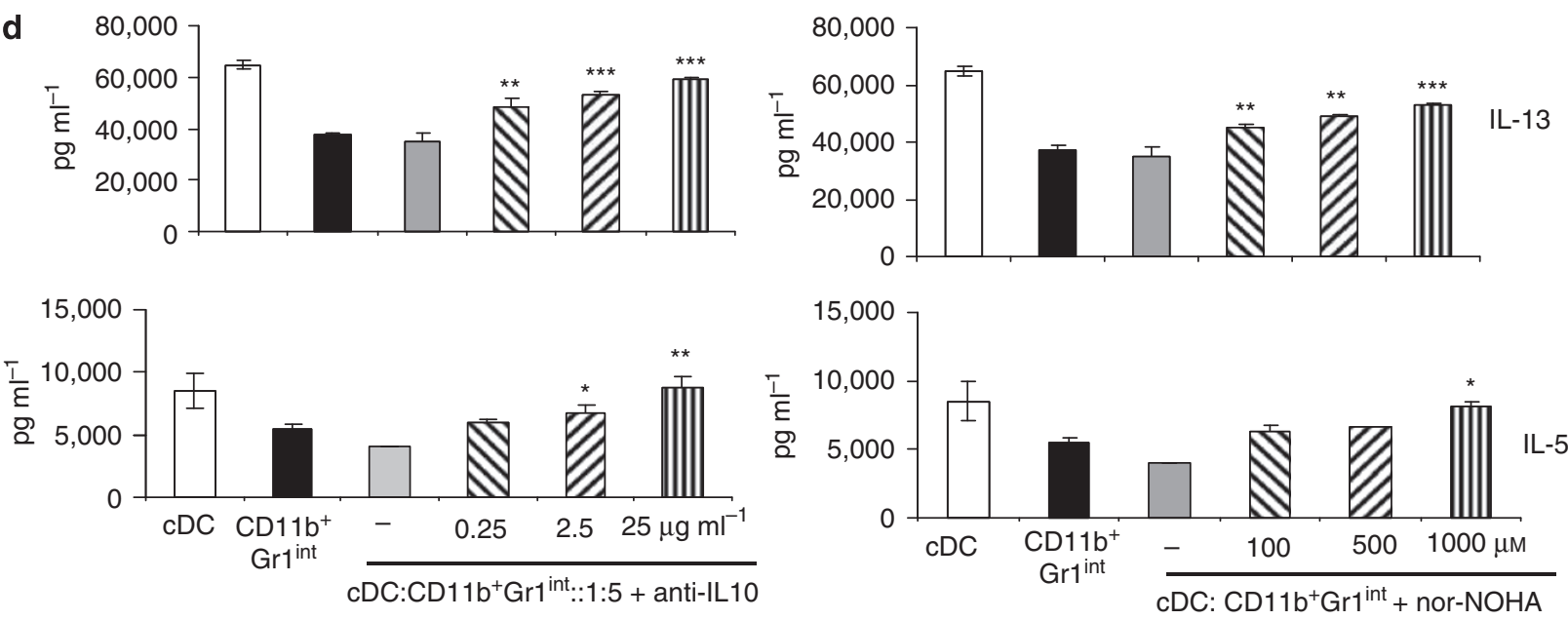

Figure $6 \mathrm{CD} 11 \mathrm{~b}+\mathrm{Gr} 1^{\text {int }}$ cells induced by lipopolysaccharide (LPS) administration suppress T-helper 2 (Th2) cell responses. Th2 cells were generated in vitro using $\mathrm{CD}^{+}{ }^{+} \mathrm{T}$ cells from DO11.10 mice by incubation under Th2-skewing conditions for 6 days. Conventional dendritic cells (cDCs) and $\mathrm{CD} 11 \mathrm{~b}^{+} \mathrm{Gr} 1^{\text {int }}$ cells were isolated from the lungs of LPS-treated mice. $\mathrm{CDCs}$ and CD $11 \mathrm{~b}^{+} \mathrm{Gr} 1^{\text {int }}$ cells alone (each at $1 \times 10^{5}$ cells per well or at fivefold more numbers of $\mathrm{CD} 11 \mathrm{~b}^{+} \mathrm{Gr} 1^{\text {int }}$ cells) or in combination as shown were cultured with Th2-polarized DO11.10 CD4 ${ }^{+} \mathrm{T}$ cells $\left(1 \times 10^{6}\right.$ cells per well) and ovalbumin (OVA) peptide $\left(5 \mu \mathrm{gml}^{-1}\right)$. (a) After cell-surface staining for CD4, intracellular cytokine staining for IL-5 was performed on cocultured cells after $36 \mathrm{~h}$. Cells were incubated with Golgi Stop (BD Biosciences) for the last $4 \mathrm{~h}$ of culture, were fixed with CytoFix/CytoPerm (BD Biosciences), permeabilized with Perm/Wash buffer (BD Biosciences), and labeled with anti-interleukin-5 (IL-5) monoclonal antibody (mAb). For analysis by flow cytometry, gating on CD4-positive cells revealed a population with lower CD4 expression and blast-like forward scatter (FSC) vs. side scatter (SSC) properties (not shown), consistent with activated T cells. In each dot plot, the number represents the proportion of IL-5-producing cells (indicated by the box) among activated CD4-positive cells. (b) Cells were stimulated with IL-2 $\left(50 \mathrm{U} \mathrm{ml}^{-1}\right)$ for $15 \mathrm{~min}$ and transducer and activator of transcription 5 (STAT5) phosphorylation determined by intracellular staining. (c) Nuclear extracts were analyzed by immunoblotting with antibodies against GATA binding protein 3 (GATA-3) and $\beta$-actin. (d) Reversal of suppression of Th2 (IL-5 and IL-13) cytokine production by arginase I (Arg1) inhibitor and anti-IL-10. Culture supernatants were analyzed by multiplex cytokine assay. Data shown are mean \pm s.d. ${ }^{\star} P<0.05,{ }^{\star \star} P<0.01,{ }^{\star \star \star} P<0.001$ with respect to $\mathrm{cDC} / \mathrm{CD} 11 \mathrm{~b}{ }^{+} \mathrm{Gr} 1^{\mathrm{int}}(1: 5 \mathrm{ratio})$. 

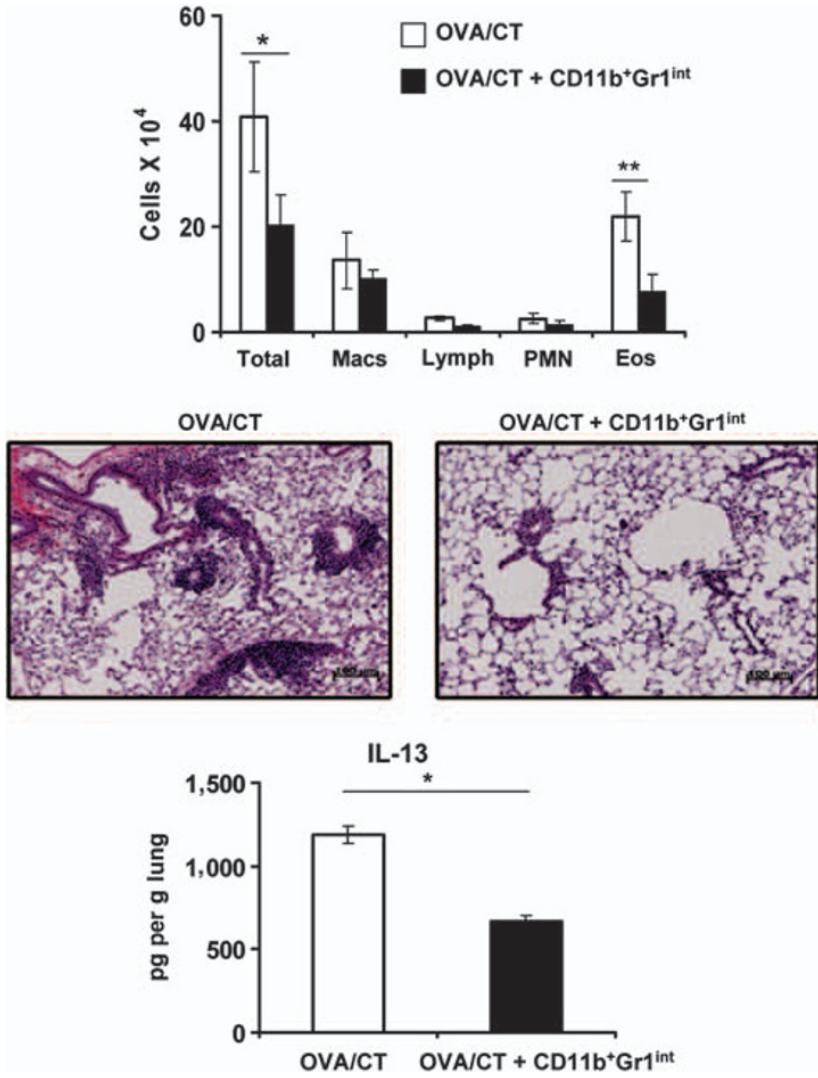

Figure $7 \mathrm{CD} 11 \mathrm{~b}+\mathrm{Gr} 1^{\text {int }}$ cell-mediated prevention and treatment of eosinophilic airway inflammation in vivo. Mice were antigen sensitized by three daily consecutive intranasal treatments with ovalbumin (OVA) plus cholera toxin (CT) followed by 5 days of rest. CD11b+Gritit cells were generated from bone marrow progenitor cells in the presence of granulocyte-macrophage colony-stimulating factor (GM-CSF; $10 \mathrm{ng} \mathrm{ml}^{-1}$ ) and lipopolysaccharide (LPS; $1 \mu \mathrm{g} \mathrm{ml}^{-1}$ ) and then adoptively transferred intratracheally ( $1 \times 10^{6}$ cells per mouse) into mice that had received OVA/ CT. Control mice did not receive any cells. Mice were then challenged with aerosolized OVA daily for 7 days. Total and differential cell counts in the bronchoalveolar lavage (BAL) fluid (upper panel) were enumerated. Values are mean \pm s.e.m. ${ }^{\star} P<0.05$ and ${ }^{* \star} P<0.01$. Hematoxylin and eosin (H\&E) staining (middle panel) of lung sections was performed. Lung infiltrates around bronchovascular bundles were of +5 grade in animals that did not receive $C D 11 b+G r 1^{\text {int }}$ cells and +1 grade in those that did. Interleukin-13 (IL-13) present in lung homogenates (lower panel) was measured by enzyme-linked immunosorbent assay (ELISA) and presented as the mean value \pm s.e.m. ${ }^{*} P<0.05$.

would have the ability to suppress recall responses to an allergen. We used OVA in combination with the mucosal adjuvant cholera toxin that we have previously shown to induce allergic airway inflammation. ${ }^{39,40}$ In vitro-generated $\mathrm{CD} 11 \mathrm{~b}^{+} \mathrm{Gr} 1^{+}$cells (Figure 7) or LPS-induced cells isolated from the lung (Supplementary Figure S4 online) were transferred into mice sensitized with OVA plus cholera toxin. At $24 \mathrm{~h}$ after the transfer of cells, mice were challenged over a span of 7 days with aerosolized 1\% OVA. Control mice did not receive any cells. As shown in Figure 7 and in Supplementary Figure S4 online, transfer of $\mathrm{CD} 11 \mathrm{~b}^{+} \mathrm{Gr} 1^{+}$ cells significantly reduced eosinophilic inflammation and IL-13 production in the lung, suggesting the potential of these cells in therapeutic intervention of allergic airways disease.

\section{DISCUSSION}

In recent years, the notion that microbial products thwart the development of allergic disease by causing Th2 to Th1 immune deviation has not been supported by scientific evidence. For example, worm infections that induce Th2 responses were also found to be inversely associated with allergic disease, which itself is a Th2-dominated disease. ${ }^{41}$ Given that immunosuppressive mechanisms are now thought to be more likely involved in mediating the protective effects of microbial products, ${ }^{42}$ we explored the possibility that LPS-induced TLR signaling promotes the development of suppressive cells in the lung, as multiple studies have established an inverse relationship between the level of LPS exposure and the development of asthma and allergy. ${ }^{4,8,9}$

LPS/TLR4 exerts a range of effects on allergic responses in the lung depending on the target cell and dose. Studies published recently show that TLR4 signaling in lung epithelial cells is important for HDM-induced allergic responses in the lung. Der $\mathrm{p} 2$, an important allergen of HDM, was able to substitute for the TLR4-associated adaptor, MD-2, that is not expressed by lung epithelial cells, thereby providing this essential component of LPS-induced TLR4 signaling in these cells. ${ }^{22}$ Another study has also reported on the importance of TLR4 signaling in epithelial cells in HDM-induced allergic airways disease. ${ }^{23}$ With regard to the level of exposure, at very low levels ( $<10 \mathrm{ng}$ ) LPS induces suppression, ${ }^{43}$ whereas at levels of $\sim 100 \mathrm{ng}$, LPS promotes Th2mediated inflammation because of its adjuvant effects. ${ }^{8}$ A high dose of LPS is suppressive for allergic responses in the airways, as shown in multiple studies ${ }^{8,9}$ including this study, but the mechanism has not been investigated before this study.

We have identified a population of LPS-induced CD11b ${ }^{+} \mathrm{Gr} 1^{\text {int }}$ $\mathrm{F} 4 / 80^{+}$cells in the lung that does not traffic to lung-draining LNs. Indeed, no effect of LPS on T-cell responses such as CD4 Tcell proliferation or Th2 priming was evident in the lung-draining LNs. However, allergen-induced inflammation in the airways was dampened when the allergen was mixed with LPS, and upon adoptive transfer, Th2-primed cells were unable to induce inflammation in LPS-exposed lungs. Together, these observations suggested suppressive effects of the cells localized to the lung tissue. When the effect of the $\mathrm{CD} 11 \mathrm{~b}^{+} \mathrm{Gr} 1^{\text {int }}$ cells on Th2-primed cells was examined in vitro, lung DC-induced GATA-3 upregulation and IL-2-induced STAT5 phosphorylation were both inhibited. The development of these cells was dependent on MyD88 but not TRIF. Lack of MyD88 unmasked the TRIF-dependent adjuvant effects of LPS even at a high LPS dose, causing LPS to promote rather than suppress HDM-induced allergic inflammation. When adoptively transferred into mice, the myeloid cells efficiently inhibited allergen-induced airway inflammation.

The cell type identified by us bears close similarity to MDSCs. Although in addition to cancers, MDSCs have been identified in various other pathological conditions, including acute and chronic infections such as worm infections $13,37,44-46$ and trauma, ${ }^{14}$ no previous study has explored the possibility that exposure of the lungs to a high dose of LPS might induce MDSC-like myeloid cells that would suppress reactivation of primed Th2 cells. In a previous study, HSPCs that had emigrated from the bone marrow were found to proliferate in extramedullary tissues such as the lung and 
respond to LPS, resulting in differentiation into $\mathrm{CD} 11 \mathrm{c}^{+}$myeloid cells, some of which coexpressed Gr1. ${ }^{7}$ Although not examined in specific models, it was suggested that the myeloid cells might have immunosurveillance functions, given that they arose in response to TLR agonists such as LPS. Our study shows that the LPS-induced lung-resident cells do have immunomodulatory functions and suppress Th2 effector function without promoting Th1 differentiation. In our experiments, lin $^{\text {neg }}$ bone marrow progenitor cells stimulated with a combination of LPS and GM-CSF but not LPS alone yielded $\mathrm{CD} 11 \mathrm{~b}{ }^{+} \mathrm{Gr} 1{ }^{\text {int }}$ cells resembling the in vivo-generated cells (Figure 5 and Supplementary Figure S2 online). Although LPS administration at a high dose alone was sufficient to promote the development of these cells in the lung, a previous study has implicated GM-CSF in the effects of LPS in the lung. ${ }^{47}$ Thus, similar to the ability of GM-CSF to promote LPS-mediated development of these cells in vitro, GM-CSF most likely is also involved in the generation of these cells in vivo. On the basis of the data shown in Figure 3 on the generation of GFP ${ }^{+}$

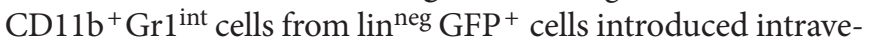
nously into animals, it is possible that HSPCs cells circulating through the lung ${ }^{7}$ respond to LPS in situ to generate these cells.

$\mathrm{Gr} 1^{+} \mathrm{CD} 11 \mathrm{~b}^{+}$cells fall into two subsets in tumor models: cells with granulocytic phenotype that express Ly6G and cells with monocytic phenotype called inflammatory monocytes expressing Ly6C. ${ }^{48}$ The two populations with granulocytic vs. monocytic characteristics might have different functions in infectious and autoimmune diseases and cancer. The majority of the LPS-induced myeloid cells in the lung expressed Ly6G, but not Ly6C, and also did not express a range of other molecules expressed by MDSCs such as CD124 and CD115. To our knowledge, there are no reports that have shown the expression of Ly6G on either inflammatory monocytes or monocyte-derived DCs. In fact, Zhu et al. ${ }^{15}$ clearly showed that $\mathrm{CD} 11 \mathrm{~b}^{+}$Ly6C ${ }^{\text {hi }}$ suppressive monocytes are Ly6G negative, further suggesting that the populations we have identified more closely resemble MDSCs. That being said, we feel that the functional distinction between inflammatory monocytes and MDSCs may blur over time as inflammatory monocytes have been shown to possess potent immunosuppressive functions. ${ }^{15,49,50}$

Continual exposure to LPS causes a selective enrichment of the $\mathrm{CD} 11 \mathrm{~b}^{+} \mathrm{Gr} 1^{\text {int }}$ cells in the tissue over cDCs because these cells, unlike the cDCs, are unable to traffic to the LNs because of lack of CCR7 expression (Figure 3). The data in Figure 6 suggest that this enrichment is necessary as similar numbers of $\mathrm{CD} 11 \mathrm{~b}^{+} \mathrm{Gr} 1^{\text {int }}$ cells as cDCs are unable to inhibit either STAT5 phosphorylation, GATA-3 expression, or cytokine production by primed Th 2 cells but fivefold more cells can. Thus, although increasing lung $\mathrm{DC} / \mathrm{T}$ cell ratio induces more cytokine expression and transcription factor activation in the T cells, the opposite is true for the $\mathrm{CD} 11 \mathrm{~b}^{+} \mathrm{Gr} 1^{\text {int }}$ cells. Moreover, when mixed with $\mathrm{cDCs}$, these cells suppress the ability of $\mathrm{cDCs}$ to reactivate primed Th2 cells (Figure 6). We have used the most conservative $\mathrm{DC} / \mathrm{CD} 11 \mathrm{~b}^{+} \mathrm{Gr} \mathrm{l}^{\text {int }}$ ratio of 1:5 in our experiments, with the numbers of these cells at the LPS dose used over a 4-day time period ranging between five- and ten-fold over $\mathrm{CDCs}$. Inhibition of Th2 cytokine production by the $\mathrm{CD} 11 \mathrm{~b}^{+} \mathrm{Gr} 1^{\text {int }}$ cells was reversed using neutralizing anti-IL-10 antibody or the specific
Arg1 inhibitor, nor-N( $\omega)$-hydroxy-nor-1-arginine. As IL-10 has been shown to induce Arg1, ${ }^{51,52}$ our data suggest that the IL$10 / \operatorname{Arg} 1$ axis is responsible for the suppressive effect of the myeloid cells on Th2 cytokine production. Interestingly, a similar suppressive effect of Arg1 on Th2 effector function was recently reported in mice infected with the helminth Schistosoma mansoni ${ }^{53}$ Mice lacking Arg1 in macrophages harbored increased levels of Th2 cytokines in the liver of infected mice that was not simply because of increased frequency of the cells..$^{53}$ The suppressive effect of Arg1 activity on Th2 effector function is interesting, given that Th2 cytokines actually stimulate Arg1 expression. ${ }^{54,55}$ Thus, it is possible that although Th2 cytokine promotes Arg1 expression, Arg1-stimulated metabolites such as polyamines may function as negative feedback regulators of Th2 effector function. We would propose that the IL-10/Arg1mediated inhibition is a dominant mechanism that overrides the activity of key regulators of Th2 cells such as GATA-3 and STAT5. This is because Th2 cytokine production was suppressed by the $\mathrm{CD} 11 \mathrm{~b}^{+} \mathrm{Gr}{ }^{\text {int }}$ cells despite the ability of the Th2 cells to mount a low level of STAT5 phosphorylation and the presence of a low level of GATA-3 in the cells. In fact, as previously shown by Paul and colleagues ${ }^{30,56}$, the low level of GATA-3 that is normally present in naive CD4+ T cells is sufficient to synergize with constitutively active STAT5 to induce Th2 cytokine production. Given that a self-amplification loop stimulated by various cytokines is thought to sustain Th2 effector cells, ${ }^{56}$ it is possible that the blunting of this response by attenuation of GATA-3 and STAT5 activation and suppression of cytokine production would also negatively affect Th2 memory. This is based on the linear model of Th2 memory in which the memory pool size is directly proportional to the effector pool size. ${ }^{57}$ Thus, it will be interesting to determine in future studies the effect of these cells on effector cell survival in vivo.

$\mathrm{CD} 11 \mathrm{~b}^{+} \mathrm{Gr} 1^{+}$cells were also identified in a model of sepsis but the cells described in this study do not seem to be the kind that we have identified in the lung as the splenic cells in the sepsis model actually promoted Th2 polarization. ${ }^{46}$ Although the sepsis model would have involved stimulation by microbial products, and indeed

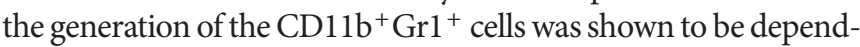
ent on MyD88-dependent signaling, the requirement for functional TLR4 was not evident in the study. ${ }^{46}$ In contrast, TLR4 was required for development of the cell in our study (Figure 5). Similar to our findings, the TRIF pathway was not involved in the generation of the splenic $\mathrm{CD} 11 \mathrm{~b}^{+} \mathrm{Gr}^{+}$cells. As despite producing high levels of IL-10, the sepsis-associated $\mathrm{CD} 11 \mathrm{~b}^{+} \mathrm{Gr} 1^{+}$cells favored Th2 development that was detrimental in the sepsis context, ${ }^{46}$ it is possible that unlike the lung cells, the splenic cells do not express Arg1.

In a recent study, prenatal exposure to a non-pathogenic bacterial species was found to protect from allergic airways disease later in the adult mice, the protective effect being dependent on multiple TLRs. ${ }^{58}$ Whether such exposures prenatally generated the kind of suppressive cell identified by us remains to be determined. In addition, whether these cells have a role in the development of regulatory $\mathrm{T}$ cells will be important to examine, given that cytotoxic T-lymphocyte antigen 4, a ligand of CD80, is expressed at high levels by regulatory T cells and is important for their functions..$^{59}$ 
In summary, our study has identified the ability of LPS to induce Th2-suppressive myeloid cells in the lung that phenotypically and functionally resemble MDSCs. In the context of allergic airways disease, these cells may have beneficial effects in inhibiting disease pathogenesis, which contrasts with the negative connotation that MDSCs have in most disease contexts. Thus, the $\mathrm{CD} 11 \mathrm{~b}^{+} \mathrm{Gr} 1^{\text {int }}$ cells may be the underlying principle of the hygiene hypothesis in the context of protection from allergic asthma. A complete understanding of the generation and regulation of these cells in the lung in response to various pathogens would provide new avenues to either promote or target these cells for therapeutic benefits to develop disease-specific immunoregulation.

\section{METHODS}

Animals and reagents. Male 6- to 8-week old BALB/c ByJ mice were purchased from the Jackson Laboratory (Bar Harbor, ME). DO11.10 transgenic mice were originally provided by Dr Kenneth Murphy at Washington University (St Louis, MO) and were bred at the animal facility at the University of Pittsburgh. The generation of MyD $88^{-/-}$ mice was previously described. ${ }^{60} \mathrm{TRIF}^{-/-}$mice were a gift of Dr Bruce Beutler at the Scripps Research Institute. All studies with mice were approved by the animal care and use committee at the University of Pittsburgh. Recombinant GM-CSF was purchased from PeproTech (Rocky Hill, NJ). LPS from Escherichia coli, strain O26:B6, was obtained from Sigma (St Louis, MO). HDM (Dermatophagoides Pteronyssinus) was purchased from Greer Laboratories (Lenoir, NC) and was stripped of LPS using Endo-Trap columns. A number of directly labeled monoclonal antibodies were used in cell phenotyping experiments as follows: phycoerythrin (PE)-labeled anti-mouse CD40 (clone 3/23), PE-labeled anti-mouse CD86 (clone GL1), APC-labeled anti-mouse CD11c (clone HL3), APC-labeled anti-mouse Gr1 (clone RB6-8C5), fluorescein isothiocyanate-labeled anti-mouse Ly6C (clone AL-21), PE-labeled anti-mouse Ly6G (clone 1A8), and neutralizing anti-mouse IL-6, all purchased from BD Biosciences (San Jose, CA). PE-labeled rat anti-mouse CD80 was purchased from Serotec (Raleigh, NC). PE-labeled anti-mouse major histocompatibility complex II (clone NIMR-4) was purchased from Southern Biotech (Birmingham, AL). PE- and APC-labeled anti-mouse F4/80, streptavidin-tricolor was purchased from Caltag Laboratories (Carlsbad, CA). L-NIL (NOS2-specific inhibitor) was purchased from Sigma-Aldrich (St Louis, MO).

Induction of allergic airway inflammation by HDM. Balb/c mice were exposed to HDM (100 $\mu$ g per mouse per treatment) intratracheally on days $0,7,14$, and 21 with or without concomitant treatment with LPS (10 $\mu \mathrm{g}$ per mouse per treatment). Lung-draining LNs were harvested 7 days after one HDM instillation \pm LPS to assess CD4 ${ }^{+}$T-cell priming. IL-5 ELISPOT assay was then performed with kit from eBioscience as per the manufacturer's specifications (San Diego, CA). In brief, ELISPOT plates (Millipore 96-well MultiScreen HTS, Billerica, MA) were coated with the capture antibody at $4{ }^{\circ} \mathrm{C}$ overnight. LN cells were plated and stimulated with phorbol-12-myristate-13-acetate $\left(25 \mathrm{ng} \mathrm{ml}^{-1}\right)$ and ionomycin (500 $\mathrm{ng} \mathrm{ml}^{-1}$ ) overnight. Biotin-conjugated detection antibody was used to detect the secreted cytokine. Plates were developed with avidin-horseradish peroxidase and peroxidase substrate (Vectastatin) and quantified with an automated ELISPOT plate reader (ImmunoSpot; Cellular Technology, Shaker Heights, OH). The number of cytokine-expressing CD4 ${ }^{+} \mathrm{T}$ cells from LN was estimated by calculation using the percentage of CD4 T cells determined by flow cytometry.

At $72 \mathrm{~h}$ after the final HDM exposure, BAL fluid and lung tissue were obtained. Lung inflammation was gauged based upon BAL fluid differential cell counts and hematoxylin and eosin and Periodic acid-Schiff staining performed on lung tissue sections. A semiquantitative method was used to score lung infiltrates. A $>3$ cell-deep infiltrate around bronchovascular bundles was a +5 grade infiltrate and +1 or lower signified a low degree of inflammation. Production of cytokines was assessed by preparation of whole lung homogenates and analysis by multiplex assay (Bioplex; Bio-Rad, Hercules, CA).

Generation of LPS-induced cells in vivo. LPS (up to $10 \mu \mathrm{g}$ per mouse per dose) was instilled intratracheally in $100 \mu \mathrm{l}$ into Balb/c mice daily for four consecutive days. At $24 \mathrm{~h}$ after the final exposure, mice were anesthetized with ketamine $\left(100 \mathrm{mg} \mathrm{kg}^{-1}\right) / x y l a z i n e ~\left(10 \mathrm{mg} \mathrm{kg}^{-1}\right)$ mixture. After exsanguinations through cardiac puncture, the aorta was severed and the pulmonary vasculature was perfused with sterile phosphate-buffered saline (PBS) plus heparin $\left(500 \mathrm{U} \mathrm{ml}^{-1}\right)$ to remove peripheral blood cells. The perfused lungs were removed, finely minced, and incubated in an enzyme solution containing $0.7 \mathrm{mg} \mathrm{ml}^{-1}$ collagenase A (Boehringer Mannheim (Roche), Indianapolis, IN) and $30 \mu \mathrm{g} \mathrm{ml}^{-1}$ type IV bovine pancreatic DNase I (Sigma-Aldrich) for $60 \mathrm{~min}$ at $37^{\circ} \mathrm{C}$. Digested lung tissue was pressed through a $70 \mu \mathrm{m}$ cell strainer and the filtered cells were further enriched by positive selection using magnetic bead separation with anti-CD11b microbeads and an AutoMACs automated cell separation instrument (Miltenyi Biotec, Auburn, CA). CD11b ${ }^{+}$cells were then stained with APC-labeled anti-Gr1 and PE-labeled anti-F4/80 antibodies (BD Biosciences). Cells expressing F4/80 and an intermediate level of $\mathrm{Gr} 1\left(\mathrm{Gr} 1^{\text {int }} \mathrm{F} 4 / 80^{+}\right)$, and cells expressing a high level of $\mathrm{Gr} 1$ but no F4/80 ( $\mathrm{Gr} 1^{\mathrm{hi}}$ polymorphonuclear; neutrophils) were isolated by fluorescence-activated cell sorting using a BD Biosciences FACSAria flow cytometer running FACSDiva software.

cDCs were isolated from mouse lungs. Single cell lung suspensions were prepared as above except that magnetic bead selection was performed using anti-CD11c microbeads. Then, CD11 $\mathrm{c}^{+}$cells, with low autofluorescence detected by the E PMT of the FACSAria cytometer, were sorted from highly autofluorescent cells (largely CD11c ${ }^{+}$alveolar macrophages) and were used as $\mathrm{cDCs}$.

Cytokine production from $\mathrm{CD} 11 \mathrm{~b}^{+} \mathrm{Gr} 1^{\text {int }}$ cells and DCs was assessed by culturing the cells overnight at $37^{\circ} \mathrm{C}$ and then examining culture supernatants by multiplex cytokine assay (Bio-Rad).

Generation of DCs and CD11b ${ }^{+} \mathrm{Gr}^{+}{ }^{+}$cells from bone marrow cells in vitro. Femurs of mice were aseptically removed and cleaned of surrounding muscle tissue. Bone marrow cells flushed from the femurs using PBS were grown in RPMI medium (Gibco, Carlsbad, CA) supplemented with $10 \%$ heat-inactivated fetal bovine serum (Gemini), $100 \mathrm{U} \mathrm{ml}^{-1}$ of penicillin and $100 \mu \mathrm{g} \mathrm{ml}^{-1}$ of streptomycin sulfate (Gibco), $1 \mathrm{mM}$ sodium-pyruvate (Gibco), and $50 \mu \mathrm{M} 2$-mercaptoethanol (Sigma, Carlsbad, CA). The cultures were supplemented with $10 \mathrm{ng} \mathrm{ml}^{-1}$ of GMCSF in the absence or presence of LPS (Escherichia coli, strain O26:B6) and were incubated for 8 to 9 days at $37^{\circ} \mathrm{C}$. At the end of the culture period, non-adherent cells were collected and purified by magnetic bead positive selection (Miltenyi Biotec) for CD11c-expressing cells in the case of cultures with GM-CSF alone, or for Thy1.2-expressing cells with LPS + GM-CSF-treated cultures. Similar cultures were also started from lineage ${ }^{\text {neg }}$ cells enriched using a lineage depletion kit (Miltenyi Biotec). Cell purity, assessed by flow cytometry, was $>95 \%$ in both the cases. $\mathrm{CD} 11 \mathrm{c}^{+}$cells were considered to be conventional bone marrow DCs.

Development of $\mathrm{CD} 11 \mathrm{~b}+\mathrm{Gr} 1{ }^{+}$cells in the lung from lineage ${ }^{\text {neg }}$ progenitor cells from UBC-GFP transgenic mice in the presence of LPS. The lineg population of bone marrow cells was enriched from transgenic (UBC-GFP) mice (Jackson Laboratories, stock no. 004353). These transgenic mice express enhanced green fluorescent protein (GFP) under the direction of the human ubiquitin $\mathrm{C}$ promoter. GFP expression is uniform within a cell-type lineage and remains constant throughout development. This $\mathrm{GFP}^{+}$lin ${ }^{\text {neg }}$ population was then transferred intravenously into naive C57BL/6 mice. Mice were divided into two groups and one group then received three daily treatments of $10 \mu \mathrm{g}$ LPS, whereas the 
other group was left untreated. The percentage of cells expressing intermediate (int) levels of Gr1 was determined in the presence or absence of LPS by flow cytometric analysis.

Phenotypic evaluation of $\mathrm{CD} 11 \mathrm{~b}+\mathrm{Gr} 1^{\text {int }}$ cells and $\mathrm{CDCs}$. The surface phenotype of cells was assessed by flow cytometry using standard methods. In brief, cells were first incubated with unlabeled CD16/CD32 monoclonal antibody (Fc block) for $5 \mathrm{~min}$ on ice, then with specifically conjugated monoclonal antibodies for an additional $15 \mathrm{~min}$. In all cases, control staining with appropriate, matched isotype control antibodies was similarly performed. All incubations were conducted at $4^{\circ} \mathrm{C}$ in PBS supplemented with $2 \%$ fetal bovine serum. Analysis was carried out on a BD Biosciences FACSCalibur flow cytometer using CellQuest Pro software. Propidium iodide, used to exclude dead cells, was added just before data collection, and at least 10,000 events within the live cell gate were acquired for each sample.

Colorimetric assay for NO. NO production by DCs and CD $11 b^{+} \mathrm{Gr} 1^{\text {int }}$ cells was measured using a commercially available colorimetric assay (Oxford Biomedical Research, Oxford, MI) as per the manufacturer's instructions. This kit uses the NADPH-dependent enzyme nitrate reductase for conversion of nitrate to nitrite before quantitation using Griess reagent, thus providing for accurate determination of total $\mathrm{NO}$ production.

Proliferation of adoptively transferred $\mathrm{CD}^{+}{ }^{+} \mathrm{T}$ cells. $\mathrm{CD} 4^{+} \mathrm{T}$ cells isolated from spleen cells of DO11.10 mice using anti-CD4 magnetic microbeads (Miltenyi Biotec) were labeled with CFSE (Molecular Probes, Carlsbad, CA), and $5 \times 10^{6}$ labeled cells were adoptively transferred intravenously to naive mice or LPS-treated (four consecutive daily intratracheal injections of $10 \mu \mathrm{g}$ per treatment LPS) mice. At $24 \mathrm{~h}$ after the adoptive transfer, mice received two consecutive daily intranasal treatments with OVA plus cholera toxin ( $1 \mu \mathrm{g}$ per mouse per treatment). After 1 day, total lung-draining LN cells were harvested and assessed for dilution of CFSE by flow cytometry. OVA-specific DO11.10 T cells were identified by staining with anti-clonotypic KJ-126 antibody (BD Pharmingen, San Diego, CA).

Generation and adoptive transfer of Th2 cells before antigen challenge. To generate Th2 cells, $\mathrm{CD} 4^{+} \mathrm{T}$ cells from $\mathrm{DO} 11.10 \mathrm{~T}$ cell receptor transgenic mice were cultured with APCs (T cell-depleted splenocytes), OVA-peptide $\left(5 \mu \mathrm{g} \mathrm{ml}^{-1}\right)$, IL-4 $\left(20 \mathrm{ng} \mathrm{ml}^{-1}\right)$, IL-2 $\left(5 \mathrm{U} \mathrm{ml}^{-1}\right)$, and anti-interferon- $\gamma\left(1 \mu \mathrm{g} \mathrm{ml}^{-1}\right)$ as described previously. ${ }^{19}$ Cultures were maintained for 5 days and re-stimulated again for 3 days under the same $\mathrm{T}_{\mathrm{H}} 2$ conditions. The Th2-skewed nature of these cells was verified based upon production of Th2 cytokines, and expression of the $\mathrm{T}_{\mathrm{H}}$ 2-specific nuclear transcription factor GATA-3 (data not shown). $\mathrm{T}_{\mathrm{H}} 2$ cells were collected, washed with $\mathrm{PBS}$, and injected intravenously into naive and LPS treated mice $\left(5 \times 10^{6}\right.$ cells per mouse). Beginning 1 day after cell transfer, mice were challenged with aerosolized OVA (1\% in PBS) for 20 min daily for 7 days using an ultrasonic nebulizer (Omron Healthcare, Bannockburn, IL). At $24 \mathrm{~h}$ after the final OVA challenge, BAL fluid and lung tissue were obtained and processed as described above.

Effect of adoptively transferred $\mathrm{CD} 11 \mathrm{~b}{ }^{+} \mathrm{Gr} 1^{\text {int }}$ cells on allergic airway inflammation. Mice were sensitized by intranasal administration of OVA/CT for 3 consecutive days and then were rested for 5 days. After the rest period, $1 \times 10^{6}$ in vitro or in vivo-generated $\mathrm{CD} 11 \mathrm{~b}^{+} \mathrm{Gr} 1^{\text {int }}$ (see above) cells were adoptively transferred intratracheally into each mouse. Beginning 1 day after transfer, mice were challenged by exposure to aerosolized OVA for 7 consecutive days. At $24 \mathrm{~h}$ after the final OVA challenge, BAL fluid and lung tissue were obtained and processed as described above.

Statistical analyses. Comparisons of means \pm s.d. or \pm s.e.m. were performed using one-way analysis of variance and Student $t$-test with
GraphPad Prism software (La Jolla, CA). Differences between the groups were considered significant if $P<0.05$.

SUPPLEMENTARY MATERIAL is linked to the online version of the paper at http://www.nature.com/mi

\section{ACKNOWLEDGMENTS}

This work was supported by US National Institutes of Health grants HL 060207 and HL 069810 (to PR), HL 077430 and Al 048927 (to AR), HL 084932 (to PR and AR), and grants from the American Heart Association, AHA 0865379D (to MA) and American Lung Association, RG-49737-N (to TBO). We thank S Akira for the kind gift of MyD88-/- mice, Y Zhang and $\mathrm{M}$ Porter for assistance with multiplex assay, and $\mathrm{A}$ Khare for critical reading of the paper.

\section{DISCLOSURE}

The authors declared no conflict of interest.

\section{C) 2010 Society for Mucosal Immunology}

\section{REFERENCES}

1. Strachan, D.P. Hay fever, hygiene, and household size. Br. Med. J. 299, 1259-1260 (1989).

2. Shirakawa, T., Enomoto, T., Shimazu, S. \& Hopkin, J.M. The inverse association between tuberculin responses and atopic disorder. Science 275, 77-79 (1997).

3. Ball, T.M. et al. Siblings, day-care attendance, and the risk of asthma and wheezing during childhood. N. Engl. J. Med. 343, 538-543 (2000).

4. Braun-Fahrlander, C. et al. Environmental exposure to endotoxin and its relation to asthma in school-age children. N. Engl. J. Med. 347, 869-877 (2002).

5. Yabuhara, A. et al. TH2-polarized immunological memory to inhalant allergens in atopics is established during infancy and early childhood. Clin. Exp. Allergy 27, 1261-1269 (1997).

6. Jacobson, D.L., Gange, S.J., Rose, N.R. \& Graham, N.M. Epidemiology and estimated population burden of selected autoimmune diseases in the United States. Clin. Immunol. Immunopathol. 84, 223-243 (1997).

7. Massberg, S. et al. Immunosurveillance by hematopoietic progenitor cells trafficking through blood, lymph, and peripheral tissues. Cell 131, 994-1008 (2007)

8. Eisenbarth, S.C. et al. Lipopolysaccharide-enhanced, toll-like receptor 4-dependent Thelper cell type 2 responses to inhaled antigen. J. Exp. Med. 196, 1645-1651 (2002).

9. Rodriguez, D. et al. Bacterial lipopolysaccharide signaling through Toll-like receptor 4 suppresses asthma-like responses via nitric oxide synthase 2 activity. J. Immunol. 171, 1001-1008 (2003).

10. Bliss, S.K., Butcher, B.A. \& Denkers, E.Y. Rapid recruitment of neutrophils containing prestored IL-12 during microbial infection. J. Immunol. 165, 4515-4521 (2000)

11. Hidalgo, A. et al. Heterotypic interactions enabled by polarized neutrophil microdomains mediate thromboinflammatory injury. Nat. Med. 15, 384-391 (2009).

12. Youn, J.I., Nagaraj, S., Collazo, M. \& Gabrilovich, D.I. Subsets of myeloid-derived suppressor cells in tumor-bearing mice. J. Immunol. 181, 5791-5802 (2008)

13. Gabrilovich, D.I. \& Nagaraj, S. Myeloid-derived suppressor cells as regulators of the immune system. Nat. Rev. Immunol. 9, 162-174 (2009).

14. Makarenkova, V.P., Bansal, V., Matta, B.M., Perez, L.A. \& Ochoa, J.B. CD11b +/Gr-1 + myeloid suppressor cells cause T cell dysfunction after traumatic stress. J. Immunol. 176, 2085-2094 (2006).

15. Zhu, B. et al. CD11b + Ly-6C(hi) suppressive monocytes in experimental autoimmune encephalomyelitis. J. Immunol. 179, 5228-5237 (2007).

16. Yang, R. et al. CD80 in immune suppression by mouse ovarian carcinoma-associated Gr-1 + CD11b + myeloid cells. Cancer Res. 66 6807-6815 (2006)

17. Kohl, J. et al. A regulatory role for the C5a anaphylatoxin in type 2 immunity in asthma. J. Clin. Invest. 116, 783-796 (2006).

18. Mackay, C.R., Marston, W.L. \& Dudler, L. Naive and memory T cells show distinct pathways of lymphocyte recirculation. J. Exp. Med. 171, 801-817 (1990). 
19. Cohn, L., Homer, R.J., Marinov, A., Rankin, J. \& Bottomly, K. Induction of airway mucus production by Thelper 2 (Th2) cells: a critical role for interleukin 4 in cell recruitment but not mucus production. J. Exp. Med. 186, 1737-1747 (1997).

20. Das, J. et al. A critical role for NF-kappa B in GATA3 expression and TH2 differentiation in allergic airway inflammation. Nat. Immunol. 2, 45-50 (2001).

21. Ishii, K.J. et al. CpG-activated Thy $1.2+$ dendritic cells protect against lethal Listeria monocytogenes infection. Eur. J. Immunol. 35, 2397-2405 (2005)

22. Trompette, A. et al. Allergenicity resulting from functional mimicry of a Tolllike receptor complex protein. Nature 457, 585-588 (2009).

23. Hammad, $H$. et al. House dust mite allergen induces asthma via Toll-like receptor 4 triggering of airway structural cells. Nat. Med. 15, 410-416 (2009).

24. Hoebe, K. et al. Upregulation of costimulatory molecules induced by lipopolysaccharide and double-stranded RNA occurs by Trif-dependent and Trif-independent pathways. Nat. Immunol. 4, 1223-1229 (2003).

25. Zhang, D.-H., Cohn, L., Ray, P., Bottomly, K. \& Ray, A. Transcription factor GATA-3 is differentially expressed in Th1 and Th2 cells and controls Th2-specific expression of the interleukin-5 gene. J. Biol. Chem. 272, 21597-21603 (1997)

26. Zhang, D.H. et al. Inhibition of allergic inflammation in a murine model of asthma by expression of a dominant-negative mutant of GATA-3. Immunity 11, 473-482 (1999).

27. Zheng, W.-P. \& Flavell, R.A. The transcription factor GATA-3 is necessary and sufficient for Th2 cytokine gene expression in CD4 T cells. Cell 89, 587-596 (1997)

28. Lee, H.J., O'Garra, A., Arai, K.-I. \& Arai, N. Characterization of cisregulatory elements and nuclear factors conferring Th2-specific expression of the IL-5 gene: a role for a GATA-binding protein. J. Immunol. 160, 2343-2352 (1998).

29. Das, J. et al. A critical role for NF-kB in Gata3 expression and Th2 differentiation in allergic airway inflammation. Nature Immunol. 2, 45-50 (2001).

30. Zhu, J., Cote-Sierra, J., Guo, L. \& Paul, W.E. Stat5 activation plays a critical role in Th2 differentiation. Immunity 19, 739-748 (2003).

31. Guo, L. et al. IL-1 family members and STAT activators induce cytokine production by Th2, Th17, and Th1 cells. Proc. Natl. Acad. Sci. USA 106, 13463-13468 (2009).

32. Weyand, C.M., Goronzy, J. \& Fathman, C.G. Modulation of CD4 by antigenic activation. J. Immunol. 138, 1351-1354 (1987).

33. Acres, R.B., Conlon, P.J., Mochizuki, D.Y. \& Gallis, B. Rapid phosphorylation and modulation of the T4 antigen on cloned helper T cells induced by phorbol myristate acetate or antigen. J. Biol. Chem. 261, 16210-16214 (1986).

34. Bingisser, R.M., Tilbrook, P.A., Holt, P.G. \& Kees, U.R. Macrophagederived nitric oxide regulates $T$ cell activation via reversible disruption of the Jak3/STAT5 signaling pathway. J. Immunol. 160, 5729-5734 (1998).

35. Mazzoni, A. et al. Myeloid suppressor lines inhibit T cell responses by an NO-dependent mechanism. J. Immunol. 168, 689-695 (2002).

36. Bronte, V. et al. IL-4-induced arginase 1 suppresses alloreactive T cells in tumor-bearing mice. J. Immunol. 170, 270-278 (2003).

37. Rodriguez, P.C. \& Ochoa, A.C. Arginine regulation by myeloid derived suppressor cells and tolerance in cancer: mechanisms and therapeutic perspectives. Immunol. Rev. 222, 180-191 (2008).

38. Nagaraj, S. et al. Altered recognition of antigen is a mechanism of CD8+ T cell tolerance in cancer. Nat. Med. 13, 828-835 (2007).

39. Krishnamoorthy, N. et al. Activation of c-Kit in dendritic cells regulates $T$ helper cell differentiation and allergic asthma. Nat. Med. 14, 565-573 (2008).
40. Oriss, T.B. et al. Dynamics of dendritic cell phenotype and interactions with CD4 + T cells in airway inflammation and tolerance. J. Immunol. 174, 854-863 (2005).

41. Yazdanbakhsh, M., Kremsner, P.G. \& van Ree, R. Allergy, parasites, and the hygiene hypothesis. Science 296, 490-494 (2002).

42. Wills-Karp, M., Santeliz, J. \& Karp, C.L. The germless theory of allergic disease: revisiting the hygiene hypothesis. Nat. Rev. Immunol. 1, 69-75 (2001).

43. Bedoret, D. et al. Lung interstitial macrophages alter dendritic cell functions to prevent airway allergy in mice. J. Clin. Invest. 119, 3723-3738 (2009).

44. Terrazas, L.I., Walsh, K.L., Piskorska, D., McGuire, E. \& Harn, D.A. Jr. The schistosome oligosaccharide lacto-N-neotetraose expands $\mathrm{Gr} 1(+)$ cells that secrete anti-inflammatory cytokines and inhibit proliferation of naive $\mathrm{CD} 4(+)$ cells: a potential mechanism for immune polarization in helminth infections. J. Immunol. 167, 5294-5303 (2001).

45. Sica, A. \& Bronte, V. Altered macrophage differentiation and immune dysfunction in tumor development. J. Clin. Invest. 117, 1155-1166 (2007).

46. Delano, M.J. et al. MyD88-dependent expansion of an immature GR$1(+) C D 11 b(+)$ population induces T cell suppression and Th2 polarization in sepsis. J. Exp. Med. 204, 1463-1474 (2007).

47. Bozinovski, S. et al. Innate immune responses to LPS in mouse lung are suppressed and reversed by neutralization of GM-CSF via repression of TLR-4. Am. J. Physiol. Lung Cell Mol. Physiol. 286, L877-885 (2004).

48. Movahedi, K. et al. Identification of discrete tumor-induced myeloidderived suppressor cell subpopulations with distinct T cell-suppressive activity. Blood 111, 4233-4244 (2008).

49. Gallina, G. et al. Tumors induce a subset of inflammatory monocytes with immunosuppressive activity on CD8 + T cells. J. Clin. Invest. 116, 2777-2790 (2006).

50. Dunay, I.R. et al. Gr1 (+) inflammatory monocytes are required for mucosal resistance to the pathogen Toxoplasma gondii. Immunity 29, 306-317 (2008).

51. Corraliza, I.M., Soler, G., Eichmann, K. \& Modolell, M. Arginase induction by suppressors of nitric oxide synthesis (IL-4, IL-10 and PGE2) in murine bone-marrow-derived macrophages. Biochem. Biophys. Res. Commun. 206, 667-673 (1995).

52. Lang, R., Patel, D., Morris, J.J., Rutschman, R.L. \& Murray, P.J. Shaping gene expression in activated and resting primary macrophages by $\mathrm{IL}-10$. J. Immunol. 169, 2253-2263 (2002).

53. Pesce, J.T. et al. Arginase-1-expressing macrophages suppress Th2 cytokine-driven inflammation and fibrosis. PLoS. Pathog. 5, e1000371 (2009).

54. Modolell, M., Corraliza, I.M., Link, F., Soler, G. \& Eichmann, K. Reciprocal regulation of the nitric oxide synthase/arginase balance in mouse bone marrow-derived macrophages by $\mathrm{TH} 1$ and $\mathrm{TH} 2$ cytokines. Eur. J. Immunol. 25, 1101-1104 (1995).

55. Munder, M. et al. Th1/Th2-regulated expression of arginase isoforms in murine macrophages and dendritic cells. J. Immunol. 163, 3771-3777 (1999).

56. Paul, W.E. \& Zhu, J. How are $T(H) 2$-type immune responses initiated and amplified? Nat. Rev. Immunol. 10, 225-235 (2010).

57. Hu, H. et al. CD4(+) T cell effectors can become memory cells with high efficiency and without further division. Nat. Immunol. 2, 705-710 (2001).

58. Conrad, M.L. et al. Maternal TLR signaling is required for prenatal asthma protection by the nonpathogenic microbe Acinetobacter Iwoffii F78. J. Exp. Med. 206, 2869-2877 (2009).

59. Wing, K. et al. CTLA-4 control over Foxp3 + regulatory T cell function. Science 322, 271-275 (2008).

60. Adachi, O. et al. Targeted disruption of the MyD88 gene results in loss of IL-1- and IL-18-mediated function. Immunity 9, 143-150 (1998). 